\title{
CULTURE AND GENDER ALLOCATION OF TASKS: SOURCE COUNTRY CHARACTERISTICS AND THE DIVISION OF NON-MARKET WORK AMONG US IMMIGRANTS
}

\author{
Francine D. Blau \\ Lawrence Kahn \\ Matthew L. Comey \\ Amanda R. Eng \\ Pamela A. Meyerhofer \\ Alexander Willén \\ Working Paper 26931 \\ http://www.nber.org/papers/w26931 \\ NATIONAL BUREAU OF ECONOMIC RESEARCH \\ 1050 Massachusetts Avenue \\ Cambridge, MA 02138 \\ April 2020
}

The authors thank Claudia Olivetti and session participants at the American Economic Association meetings, Atlanta, Georgia, January 2019. The views expressed herein are those of the authors and do not necessarily reflect the views of the National Bureau of Economic Research.

NBER working papers are circulated for discussion and comment purposes. They have not been peer-reviewed or been subject to the review by the NBER Board of Directors that accompanies official NBER publications.

(C) 2020 by Francine D. Blau, Lawrence Kahn, Matthew L. Comey, Amanda R. Eng, Pamela A. Meyerhofer, and Alexander Willén. All rights reserved. Short sections of text, not to exceed two paragraphs, may be quoted without explicit permission provided that full credit, including () notice, is given to the source. 
Culture and Gender Allocation of Tasks: Source Country Characteristics and the Division

of Non-market Work among US Immigrants

Francine D. Blau, Lawrence Kahn, Matthew L. Comey, Amanda R. Eng, Pamela A. Meyerhofer, and Alexander Willén

NBER Working Paper No. 26931

April 2020

JEL No. J13,J15,J16,J22

\section{ABSTRACT}

There is a well-known gender difference in time allocation within the household, which has important implications for gender differences in labor market outcomes. We ask how malleable this gender difference in time allocation is to culture. In particular, we ask if US immigrants allocate tasks differently depending upon the characteristics of the source countries from which they emigrated. Using data from the 2003-2017 waves of the American Time Use Survey (ATUS), we find that first-generation immigrants, both women and men, from source countries with more gender equality (as measured by the World Economic Forum's Global Gender Gap Index) allocate tasks more equally, while those from less gender equal source countries allocate tasks more traditionally. These results are robust to controls for immigration cohort, years since migration, and other own and spouse characteristics. There is also some indication of an effect of parent source country gender equality for second-generation immigrants, particularly for secondgeneration men with children. Our findings suggest that broader cultural factors do influence the gender division of labor in the household.

Francine D. Blau

ILR School

Cornell University

268 Ives Hall

Ithaca, New York 14853-3901

and NBER

fdb4@cornell.edu

Lawrence Kahn

ILR School

Cornell University

258 Ives Hall

Ithaca, NY 14853

lmk12@cornell.edu

Matthew L. Comey

Department of Economics

Cornell University

443 Uris Hall

Ithaca, NY 14853

mlc349@cornell.edu
Amanda R. Eng

Department of Economics

Cornell University

2301 Martha Van Rensselaer Hall

Ithaca, NY 14853

are54@cornell.edu

Pamela A. Meyerhofer

Department of Policy Analysis and Management

2305 Martha Van Rensselaer Hall

Cornell University

Ithaca, NY 14850

pam299@cornell.edu

Alexander Willén

Department of Economics

Norwegian School of Economics

Helleveien 30

5045 Bergen

Norway

alexander.willen@nhh.no 


\section{Introduction}

As female labor force participation has increased, the female share of non-market or household work has gained attention in the gender inequality literature (e.g., Burda, Hamermesh, and Weil, 2013; Bianchi, Milkie, Sayer, and Robinson, 2000; Coltrane, 2000; Ralsmark, 2017). Like the gender wage gap and male-female differences in labor force participation, the gender gap in housework has also decreased, with much of the reduction reflecting decreases in women's housework time (Bianchi, Milkie, Sayer, and Robinson, 2000). While men's housework time increased through the 1980s, there has been little subsequent change (Bianchi, Milkie, Sayer, and Robinson, 2000; Blau and Kahn, 2007; and Blau and Winkler, 2018). Despite some convergence, women continue to perform a disproportionate amount of housework and childcare. This leads to many employed women taking on a "second shift" in the household (Hochschild, 1989). For example, in 2014, employed married women spent somewhat less time on market work but considerably more time on work in the home than employed married men, resulting in an average of 4.6 hours more of total work—defined as housework plus market work-for women. ${ }^{1}$

More broadly, women's greater responsibility for housework and caregiving may be associated with decisions that reduce their labor market success compared to men's, including weaker labor force attachment (Mincer and Polachek, 1974), a lesser willingness to work long hours (Goldin, 2014), restricted job search and commuting time (Le Barbanchon, Rathelot, and Roulet, 2019; Butikofer, Løken, and Willén, 2019), or supplying less effort for similar hours worked (Becker, 1985). These decisions, as well as decisions regarding, for example, part-time work, and matches to occupations and firms are likely implicated in the "child penalty": a

\footnotetext{
${ }^{1}$ Calculated from Blau and Winkler (2018), Table 4.1, p. 68.
} 
decrease in women's earnings relative to men's earnings associated with the arrival of children (e.g., Kleven, Landais, and Søgaard, 2019; Waldfogel, 1998). ${ }^{2}$

In an effort to more fully understand the determinants of the household division of labor and how malleable that division is, we explore the impact of source-country culture specifically gender norms - on the levels of male and female household labor supplied by firstand second-generation immigrants in the United States (the first generation refers to the immigrants themselves, the second generation to their native-born children). By culture, we mean beliefs and preferences related to gender norms that originate in the immigrant's sourcecountry. ${ }^{3}$ In the remainder of the paper, we will use the terms culture and gender norms interchangeably. The relationship between culture and the household division of labor is of particular interest because, as the proportion foreign born continues to rise, the influence of source country culture will continue to play a large role in the future of gender equality in the United States (Blau, Kahn, and Papps, 2011). Specifically, this project studies the effect of source country gender equality on the gender division of household labor and which types of tasks (housework or childcare) drive any differences. To examine this question, we use the 2003-2017 waves of the American Time Use Survey (ATUS) to measure non-market work and the Global Gender Gap Index (GGI) from the World Economic Forum to measure culture and gender norms in source countries. ${ }^{4}$ The GGI is comprised of a variety of indictors that measure social, political, and economic equality of men and women. We further control for source

\footnotetext{
${ }^{2}$ For evidence that housework reduces wages, see, for example, Hersch (2009). We note that demand-side factors like discrimination against mothers may also play a role in the child penalty, see, Correll, Benard, and Paik (2007).

${ }^{3}$ We follow Fernández and Fogli (2009) in defining culture in terms of beliefs and preferences.

${ }^{4}$ The GGI has been used as an indicator of gender equality in a number of other studies. See, for example, Guiso, Monte, Sapienza, and Zingales (2008); Zentner and Mitura (2012); Fryer and Levitt (2010); and Nollenberger, Rodríguez-Planas, and Sevilla (2016).
} 
country fertility and GDP per capita in an effort to isolate the cultural factors picked up by the GGI. $^{5}$

We find that female immigrants from more gender equal countries, as measured by a higher GGI, spend significantly fewer hours per week on non-market work, allocating less time to both housework and childcare. Among second-generation women, parents' source country GGI has no statistically significant impact on non-market work, though the signs are in the expected direction. An additional important contribution of this paper is that we also examine how source country characteristics influence men's time allocation, whereas much of the previous work on source country gender roles and immigrant behavior focuses primarily on women. We find that men from more gender equal countries do higher levels of non-market work, including both housework and childcare. Further, second-generation men — particularly those with children — whose parents came from more gender equal countries spend significantly more time on housework and childcare than their counterparts from more traditional countries.

A concern with our research design is that the identified differences in the non-market work allocation of immigrant men and women from high- and low-GGI countries may be driven by selection. That is, perhaps couples choosing to migrate from low-GGI countries disproportionally allocate non-market work to women relative to the typical couple from those countries, while couples choosing to migrate from high-GGI countries disproportionally allocate non-market work to men relative to the typical couple from those countries. However, for such selection to be consistent with our findings, any country-related selection biases would have to operate substantially differently in low- compared to high-GGI countries, with immigration being selective of the most traditional couples from low-GGI countries and the least traditional

\footnotetext{
${ }^{5}$ The GGI is intentionally designed to not measure overall levels of economic development.
} 
couples from the high-GGI countries. Below, we provide a detailed discussion of why we believe these selection patterns to be unlikely.

We conclude our analysis by exploring how immigrant status and source country gender equality are related to the non-market work "penalty" faced by wives who violate the male breadwinner norm, extending analysis by Bertrand, Kamenica, and Pan (2015). We find that this penalty is significantly larger for immigrant women than native women: immigrant wives that just outearn their husbands do 4.5 additional hours of non-market work, while their native counterparts only do an additional 1.5 hours of non-market when just outearning their husbands. While we do not find a significant effect of the GGI on the size of this penalty for women, we do find that men from more gender-equal source countries are significantly less prone to reducing non-market work when they are outearned by their wives.

\section{Relationship to Previous Literature}

Coltrane (2000) summarizes the research findings on household division of labor from the 1990 s as women reducing, men increasing, but women still doing considerably more housework. Bianchi, Milkie, Sayer, and Robinson (2000) and Bianchi, Sayer, Milkie, and Robinson (2012) confirm this finding through the early 2000s: though women have cut their housework hours and men have increased theirs since the mid-1960s, women still did 63.3

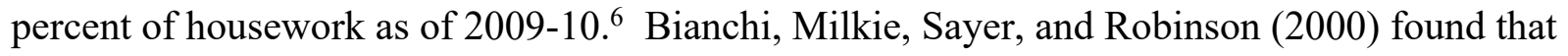
about half of the decreases in women's housework could be accounted for through compositional changes — such as increased labor force participation, later marriages, and fewer children — while relatively little (15 percent) of the male increase in housework could be accounted for by such

\footnotetext{
.$^{6}$ Blau and Winkler (2018), Table 4.1, present similar results for 2014-with married women doing 63.2 percent of housework.
} 
compositional changes. With respect to childcare, researchers find a similar persistence of unequal gender division of labor. Although parents of both genders spend more time with their children now than they did in the 1960s, mothers still devote more time to childcare than fathers (Gauthier, Smeeding and Furstenberg, 2004; and Bianchi, Milkie, Sayer and Robinson, 2012). Beyond these broader time trends, previous research has also focused on determinants of cross-sectional variation in parents' household time. Education has emerged as a major factor. In particular, highly educated American parents spend more time with their children relative to other education groups, despite also working more outside the home (Guryan, Hurst, and Kearney, 2008). Education also tends to be positively associated with more egalitarian attitudes towards gender roles (see, e.g., Campbell and Horowitz, 2016; Cunningham, 2008; Kosteas, 2013; Davis and Greenstein, 2009; and Ralsmark, 2017). ${ }^{7}$

We contribute to the literature on gender differences in the allocation of non-market work by exploring the impact of an explicit measure of culture on the gender division of non-market work. Our results are of interest in suggesting an important and persistent effect of cultural factors on this division. Moreover, as the proportion foreign born continues to rise, our results imply that the influence of source country culture likely will continue to play a role in the future of gender equality in the United States.

While the literature cited above on the household division of labor does not distinguish between the behavior of immigrants and natives, there exists a large literature concerning how immigrants and their native-born children (the second generation) assimilate to gender norms in the United States, primarily focusing on fertility and labor supply. Blau (1992) found a positive

\footnotetext{
${ }^{7}$ Interestingly, using data on 15 European countries, Ralsmark (2017) found that mandatory increases in education reduced agreement with the gender norm that men should be the breadwinner ("When jobs are scarce, men should have more right to a job than women"), but not the norm that women should be the homemaker ("A woman should be prepared to cut down on her paid work for the sake of her family.")
} 
effect of source country fertility rates on immigrant women's fertility, and Antecol (2000) found that source country female labor force participation rates were positively correlated with US labor force participation of immigrant women. Blau, Kahn, and Papps (2011) identified a significant relationship between the assimilation of immigrant women's labor supply and gender roles in the source country: immigrant women from countries with high female labor supply persistently work more than those from low female labor supply countries and fully assimilate to native participation levels, while women from low female labor supply countries shrink the labor supply gap with natives over time but never fully close it. Blau and Kahn (2015) confirm that source country female labor supply affects labor supply in the host country even after controlling for the immigrants' own labor supply prior to immigration. ${ }^{8}$ Blau, Kahn, Brummund, Cook, and Larson-Koester (forthcoming) examine the impact of son preference on fertility decisions, finding stronger evidence of son preference for immigrants from less gender equal source countries (i.e., countries with a lower value of the GGI).

With respect to the descendants of immigrants, Antecol (2000) found a positive correlation between US and source country labor force participation for "second and higher generation" immigrants, defined by their answer to the 1990 Census question on ancestry, although the effect was weaker than it was for first-generation immigrants. Similarly, the labor supply and fertility behavior of US-born daughters of immigrants (the second generation) has been found to be positively associated with female labor force participation and fertility rates in their parents' country of origin (Fernández and Fogli, 2009; and Blau, Kahn, Liu and Papps,

\footnotetext{
${ }^{8}$ Research on other countries confirms the positive relationship between source country female labor supply and immigrant women's labor supply in the host country. Using labor force participation of the source country as a proxy for norms about women's roles, Bredtmann and Otten (2013) find that higher source country labor force participation increases immigrant women's labor supply in their host country using immigrants from 26 European countries in the European Social Survey.
} 
2013). Finally, the Blau, Kahn, Brummund, Cook, and Larson-Koester (forthcoming) finding of stronger evidence of son preference in fertility decisions for immigrants from less gender equal source countries extends to second-generation immigrants whose parents are from such countries.

We contribute to this literature on immigrants and the second generation by exploring the role of source country gender equality on the allocation of non-market work between men and women within the household. We find such an association and further confirm that it is not simply a reflection of immigrant labor supply decisions.

\section{Theoretical Framework}

We conceptualize the household time allocation decision in the spirit of Becker (1965) and Mincer (1962). That is, we consider a married couple maximizing total household utility by choosing how to allocate the wife's and husband's time between market work and non-market work. By allocating time to market work, the household earns wages that can be converted into consumption goods, and by allocating time to non-market work, the household produces household goods. Utility is then a function of these consumption and household goods. In these types of models, market productivity — reflected by a wage level — serves as a force pulling spouses toward market work, while productivity in household production serves as a force pulling spouses toward non-market work. In the context of this paper, we further consider the role of culture in this decision.

Before proceeding further, it is important to describe more explicitly what we mean by culture. We follow Fernández and Fogli (2009), who define differences in culture as "systematic differences in preferences and beliefs across either socially or geographically differentiated groups" (147). In this paper, we are particularly interested in culture as it relates to gender 
norms: attitudes about men and women's relative roles in economic, social, and political spheres. Such "systematic differences in preferences" regarding gender norms may translate to preferences about the amount of work men and women do in the market and in the household, justifying their inclusion directly into the household utility function. That is, we consider households having not only preferences for household and market good consumption, but also having preferences over the time allocation decision itself. In the appendix, we provide a stylized model of household utility and production, solving for optimal non-market work and showing how it depends on such a gender norm. ${ }^{9}$ We operationalize the gender norm as a utility penalty that is increasing in the wife's market work and decreasing in the husband's market work.

The comparative static of interest in our paper is the time allocation response to changes in the strength of the gender norm. That is, holding wages and productivity constant, how does a spouse's time allocation change with stronger or weaker gender norms? A key result in our stylized model is that the wife's non-market work increases in the strength of the gender norm and the husband's non-market work decreases in the strength of the gender norm. However, the model — and these types of models more broadly — makes explicit how the time allocation decision also depends on the wage rate and household productivity of each spouse. It is quite plausible that gender norms themselves affect wages or productivity. This foreshadows the primary empirical challenge of our paper: estimating the effect of culture on time allocation, holding constant the other factors related to market and non-market productivity. We address this challenge through the inclusion of control variables in our regressions, and we provide a

\footnotetext{
${ }^{9}$ We thank Claudia Olivetti for suggesting a model of the type we present. Note, that while the theoretical model considers wages, our empirical work is reduced form with respect to wages. The reason we do not include wages is to avoid well-known problems of estimating (imputing) a wage rate for non-labor force participants.
} 
discussion in the methods section below about how to think about the role of these control variables in the context of the model described above.

\section{Data}

To measure non-market work, we use time diary data from the 2003-2017 waves of the American Time Use Survey (ATUS) conducted by the US Bureau of Labor Statistics. ${ }^{10}$ The ATUS elicits time diary data based on respondents' recall of the previous day's activities via telephone interviews, recording each activity and time spent on each activity during a 24-hour period. Respondents are notified of the interview in advance, and the interviewer collects "a detailed account of the respondent's activities, starting at 4 a.m. the previous day and ending at 4 a.m. on the interview day." 11 Time diary data are generally agreed to be the most accurate form of time use survey data (e.g., Kan and Pudney, 2008) and even perform well compared to researcher-coded data from wearable cameras (Harms et al, 2019).

ATUS respondents are selected from the outgoing rotation group of the Current Population Survey (CPS), with adjustments to make the sample representative of the population of the United States and over-sampling of minority households. One respondent from the CPS household over the age of 14 is randomly selected to complete the interview. Because respondents can be linked to the CPS, we are able to observe not only a rich set of their own demographic information but also the same demographic information for respondents' spouses and children. The CPS also asks each individual about their parents' country of birth, allowing us to identify second-generation immigrants.

\footnotetext{
${ }^{10}$ For more information on this data set, see https://www.atusdata.org/atus/about atus.shtml and https://www.bls.gov/tus/atususersguide.pdf.

${ }^{11}$ https://www.bls.gov/tus/atusfaqs.htm\#1.
} 
We restrict our sample to married respondents in heterosexual relationships where both the respondent and the spouse are between the ages of 18 and 64 . We focus on couples because it is for this group that the time allocation decision has the most salience. We present results for all married couples to provide a bottom line for the married population. We also show separate results for families with children, because these families are making child care decisions. Since time use data are only available for one respondent in each household, we are not able to observe the time allocation of the respondent's spouse. However, by enforcing these sample restrictions, we can estimate for the population how married men and women divide household labor. ${ }^{12}$ We also exclude individuals whose diary day was a holiday, as well as natives born abroad and immigrants whose year of immigration is missing. This resulted in an analysis sample of 73,448 observations, including 12,455 immigrants.

Our dependent variables are housework, primary childcare, and total non-market work, each measured in hours per week. We study housework and primary childcare separately in addition to total non-market work since the allocation of time to childcare has changed over time and differs across education groups. Our measure of housework includes tasks such as laundry, food preparation, and cleaning, as well as exterior household activities such as lawn care and vehicle repair. It also includes household management tasks such as financial management and household organization and planning. Primary childcare is all the time spent with household children, either engaging in an activity with the children or supervising the children. This includes physical care of children, playing, helping with homework, and obtaining or providing medical care for children. This does not include time when the child was present but where the main activity during that period was not related to the child (i.e., secondary childcare). Total

\footnotetext{
${ }^{12}$ All analyses were repeated including those in heterosexual partnerships but not married and results were similar.
} 
non-market work time combines housework and primary childcare tasks while adding time spent caring for adults and time spent grocery shopping. See the Data Appendix for additional details on the construction of the sample and the time use variables.

Table 1 provides some motivation for the study by comparing mean values of total nonmarket work, housework, and childcare by immigrant generation and gender. ${ }^{13}$ The first generation is defined as individuals who are foreign born; the second generation as native-born individuals with at least one foreign-born parent; and the third-plus generation as native-born individuals both of whose parents are also native born. Overall, the data show much larger gender gaps in total non-market work and in housework for first-generation immigrants than for second-generation immigrants, whose gender gaps are relatively close to those of third-plus generation natives. This supports our expectation that immigrants are a more traditional group with respect to gender roles, on average, compared to natives, at least for time spent doing housework. The gender gap in childcare hours among those with children is more similar across generations, though somewhat higher for first- and second-generation immigrants than third-plus generation natives. In addition, based on these aggregates, there appears to be assimilation in total non-market work and housework from first- to second-generation immigrants for both women and men, with the total non-market work and housework of both second-generation men and women being quite similar to that of their third-plus-generation counterparts. Of course, similarities between second- and third-plus-generation time allocation at the mean does not rule out heterogeneity within the group of second-generation individuals related to the source countries of their parents.

\footnotetext{
${ }^{13}$ All means in this table are computed using sampling weights, which we discuss in more detail in the Methods section below. When we control for source country characteristics in the analyses restricted to first- or secondgeneration immigrants, the mean values are very similar to those shown in Table 1, with the sample size reduced only slightly due to missing data on country characteristics.
} 
The explanatory variable of interest is the Global Gender Gap Index (GGI) calculated by the World Economic Forum, our measure of source country gender norms. The measure is constructed using four equally-weighted subindexes - economic participation and opportunity, educational attainment, health and survival, and political empowerment - that are averaged to produce an index with values between 0 (total inequality) and 1 (total equality). Each subindex is comprised of various indicators of gender equality, measured in female-to-male ratios so as to represent the gap between men and women rather than the level of development in the measured country. Each indicator is weighted by an amount inversely proportional to its standard deviation, so that a standard deviation change in each indicator has the same relative impact on its respective subindex. Some of the indicators included in the index are labor force participation, wages, professional and technical employment, literacy rate, primary school enrollment, sex ratio at birth, healthy life expectancy, seats in parliament, and years as head of state. For more details on the inputs and calculation of the Index, see Hausmann, Tyson, and Zahidi (2007). To be included in the Index, a country must have data available for at least 12 of the 14 indicators in the Index. Ideally, we would use a GGI from a period prior to our sample period; however, since the GGI began in 2006, this is not possible. We use an average of the 2006 and 2007 GGI values as our measure of gender norms in the source country to create a more stable measure, while pre-dating as many of our observations as possible. ${ }^{14}$ In 2006,115 countries were included in the index, representing over 90 percent of the world's population. Immigrants from countries without a valid GGI are excluded from our sample. We match 93.8 percent of the immigrants in our sample to a valid GGI value (using sample weights). The

\footnotetext{
${ }^{14}$ In the few instances where a GGI value is not available in 2006 but is available in a later year, we use the earliest year it was available. This affects about 6 percent of the immigrants in our sample. The latest year used is 2010 , but most immigrants without a 2006 value matched to a 2007 value.
} 
average GGI in our sample is 0.66 with a minimum of 0.529 and a maximum of 0.813 . Countries such as Sweden, Norway and Finland are among the highest scoring countries, and Saudi Arabia, Pakistan and Egypt among the lowest.

As further motivation for our study, Figure 1 plots the raw relationship between a country's GGI score and the respective female-male mean total non-market work difference for immigrants from that country for countries with at least 30 ATUS observations. The figure reveals a statistically significant negative relationship between source country GGI and gender inequality in non-market work. That is, immigrants from countries with more gender equality, as measured by a higher GGI score, share non-market work activities more equally by gender, as measured by a difference closer to zero. A regression line fitted through the points has a slope coefficient of -52.54 hours of non-market work per week and is significant at better than the 5 percent level. ${ }^{15}$ Note, however, that this regression does not include any controls and weights each country equally. We explore the role of covariates in individual-level regressions in later sections. Figure 1 also gives a sense of the distribution of GGI scores, showing a majority of countries with scores between 0.60 and 0.70 and a mass of scores around 0.65 ; this compares to a score of 0.702 for the United States, providing further evidence that immigrants on average come from countries with more traditional gender roles than the United States (Blau, Kahn and Papps, 2011).

In our analyses below, we also include controls for source country fertility and GDP per capita, since these measures may affect immigrant time use decisions apart from the factors the

\footnotetext{
${ }^{15}$ As noted, for this figure, we dropped source countries with less than 30 ATUS observations to avoid showing any possibly misleading country-level differentials. Including these dropped countries in the simple bivariate regression of the non-market work gender differential on GGI yields a slope coefficient of -62.6, significant at the 1 percent level. Note that the full set of countries is included in our regression analyses below.
} 
GGI is designed to capture. Both of these variables primarily come from the World Bank. ${ }^{16}$ Since both total fertility and GDP per capita are available for a longer period than GGI, we compute country averages for these variables beginning with 2000 and continuing through 2007 so that we observe all of our source country characteristics through the same end date. All other control variables come from the ATUS and the CPS obtained from IPUMS. ${ }^{17}$

\section{Methods}

To examine in more detail the role of source country culture (or gender norms) on nonmarket work allocation, we turn to regression-adjusted results. As discussed in the theoretical framework section, the time allocation decision is a function of market and non-market productivity, as well as individual preferences. To the extent that productivity is correlated with culture, our results would be biased without proper controls. However, culture itself may be a cause of gender differences in productivity. For example, culture may influence women's attachment to the labor force through expectations related to their education and career choices. We believe these channels are interesting, but also seek estimates that represent a "purer" effect of culture. For that reason, we control for source country GDP and fertility rates and also provide a suite of regression specifications that vary in the extent to which our measure of culture can operate through variables related to individual labor market preparation and attachment.

Specifically, in our regression-adjusted results, we first provide a parsimonious specification with some basic controls (specified below) but omitting the individual's education, number of children, and spousal characteristics. This specification examines the total effect of the GGI as it impacts time allocation both directly and indirectly through these variables. We

\footnotetext{
${ }^{16}$ See the Data Appendix for information on the sources for GDP per capita for the countries for which it is missing from the World Bank data.

${ }^{17} \mathrm{See}, \mathrm{https}: / / w w w . a t u s d a t a . o r g / a t u s /$ and https://cps.ipums.org/cps/.
} 
then provide specifications that include these variables as controls in order to provide a more stringent test of the direct impact of source country culture as it relates to gender norms. However, we stress that education, own-fertility, and spousal characteristics themselves are possible outcomes of source country culture. Regression specifications that add these additional controls will give more conservative estimates of the role of culture in immigrant time allocation decisions, making us more confident that we have isolated an effect of culture per se. Thus, this is our preferred specification. We conclude our main specifications by controlling for the wife's market work, which by far is our most conservative specification. Time allocated to market and non-market work is jointly determined. We include this specification to descriptively explore the question of whether results for housework and childcare simply reflect differences in time allocated to market work or persist even after controlling for time spent in market work. The specification including the wife's market work is also robust to possible biases related to differential legal work status across men and women from different source countries (e.g., women's lower likelihood of having an employment visa). ${ }^{18}$ However, given the endogeneity of market work, our preferred specification excludes wife's market work.

Before estimating the impact of specific source country characteristics, we first benchmark the immigrant data by examining the difference between immigrants and natives in the gender division of household labor. While Table 1 shows differences in non-market work for men and women across immigrant generations, it is possible that compositional differences account for such disparities. To explore the role of composition, we estimate regressions for the

\footnotetext{
${ }^{18}$ Blau \& Kahn (2015) are able to observe visa status using the New Immigrant Survey. They find that women are somewhat more likely than men to come on a family visa and somewhat less likely than men to have an employment visa. However, visa status itself could be an outcome of culture, with gender norms determining which spouse's employment options are paramount. See the later discussion about possible selection biases on why we think this issue to be minimal.
} 
three non-market work dependent variables with controls. Specifically, we estimate separate regressions for men and women using the following OLS model:

(1) $Y_{\text {idmys }}=\beta_{0}+\beta_{1}$ Immigrant $_{i}+\beta_{2}$ Second Generation $_{i}+\beta_{3} X_{i}+\delta_{d}+\eta_{m}+\tau_{y}+$ $\theta_{s}+\epsilon_{i d m y s}$

where $Y$ is either total non-market work, housework, or primary childcare (measured in weekly hours), for individual $i$, reporting on day of the week $d$, in month $m$, of year $y$, living in state $s$. Immigrant is a dichotomous variable equal to one if the respondent was born outside the United States. ${ }^{19}$ Second Generation is a dichotomous variable equal to one if the respondent was born in the United States and at least one of the respondent's parents was born in another country. The omitted category is natives: respondents born in the United States, both of whose parents are also US born. Thus, natives correspond to the third-plus generation. In the most parsimonious specification, $X$ includes controls for the respondent's age, age squared, and race/ethnicity (measured in five mutually exclusive categories: Non-Hispanic White, Non-Hispanic Black, Non-Hispanic Asian, Non-Hispanic Other, and Hispanic, with Non-Hispanic White serving as the reference group). We then add controls for education (four discrete categories: less than High School, High School, Some College, and College+, with less than High School serving as the reference group), children (number of children in age groups 0-5, 6-12, and 13-17, respectively), and spouse characteristics (spouse age, age squared, race/ethnicity, and education). In a final specification, we add controls for the wife's usual hours of market work. ${ }^{20}$ All regressions control for day of week, month, year, and state fixed effects $\left(\delta_{d}, \eta_{m}, \tau_{y}\right.$, and $\theta_{s}$,

\footnotetext{
${ }^{19}$ For the initial immigrant-native comparisons, those born in US territories are included as immigrants. They are excluded from subsequent analyses that include source country characteristics since such variables are not available for them.

${ }^{20}$ Regressions including this variable also include an indicator variable equal to 1 if the wife's hours of market work vary from week to week in which case wife's usual hours of market work are set to 0.
} 
respectively) and $\epsilon$ is the error term. For each sex and specification, we estimate the model on a sample of all individuals (including those without children) and a sample restricted to those with at least one child under 18 in order to perform a more focused analysis.

We next focus on first- and second-generation immigrants to examine the relationship between source country characteristics and the division of labor by gender. We estimate the following OLS equation separately by gender and first- or second-generation immigrant status: (2) $Y_{\text {idmys }}=\gamma_{0}+\gamma_{1}$ Gender Gap Index $+\gamma_{2}$ Source Country Characteristics $+\gamma_{3} Z_{i}+$ $c_{d}+d_{m}+e_{y}+f_{s}+u_{i d m y s}$ where the subscripts and the dependent variables, $Y$, are defined as above. The coefficient of interest is $\gamma_{1}$, which measures the association between time allocated to non-market work activities and the Gender Gap Index (GGI). Source Country Characteristics include the fertility rate and GDP per capita variables, as detailed above. In our most parsimonious specification, $Z$ includes all the variables in the initial $X$-vector in Equation (1) and additionally includes for immigrants: years since migration and its square, as well as immigration cohort (categorized based on year of migration: pre-1970, 1970-79, 1980-89, 1990-99, 2000-09, and 2010-17, with pre-1970 as the omitted cohort). As in Equation (1), controls for education, children, spouse characteristics, and wife's market work are added in the second specification. Spouse characteristics include all the variables in $X$ for the spouse and, in addition, dummies for spouse immigrant and spouse second-generation immigrant status and interactions between the spouse immigrant dummy and the variables related to immigrant status: years since migration and its square and the immigrant cohort dummies. We include the same fixed effects from Equation (1). As above, for each gender and specification we estimate the model on a sample of all individuals and a sample restricted to those with at least one child under 18. 
Equation (2) is estimated separately for first- and second-generation immigrants. For first-generation immigrants, the source country characteristics are those of the country from which they emigrated. For second-generation immigrants, the source country characteristics are those of their parents. We are able to observe parents' birthplace by linking the ATUS data to the CPS. Second-generation immigrant respondents are assigned the source country characteristics of their mother, unless the mother's source country characteristics are missing or the mother was born in the United States. In that case, they are assigned their father's source country characteristics. We follow this procedure because the high correlation between father's and mother's birthplace when both are foreign born makes estimating separate effects of father's and mother's source country difficult in a sample of this size. (Of second-generation immigrants where both parents are foreign born, both parents are from the same source country for 87.2 percent of our sample.) We prioritize mother's birthplace because Blau, Kahn, Liu and Papps (2013) found that the effect of mother's source country characteristics (fertility and female labor supply) on second-generation women's behavior is generally larger than that of the father's source country characteristics (fertility and female labor supply). We tested prioritizing father source country characteristics and results were similar. All regressions are weighted using ATUS sampling weights adjusted so that each year receives the same weight. In regressions estimated using Equation (2), standard errors are clustered at the immigrant or parental birthplace level.

Because the GGI is an agglomeration of several equality measures, there are several culture-based interpretations for these regressions. A significant coefficient on $G G I$ could be directly indicative of attitudes about a woman's role in the household: immigrants may have explicit expectations about non-market work allocation that are reflective of source country 
culture. However, in our more parsimonious specifications, the coefficient on $G G I$ could also capture the effect of cultural attitudes about women's education and economic participation. That is, since low-GGI countries provide fewer education and economic opportunities for women, women from these countries tend to have lower potential market wages and, thus, immigrant households from low-GGI countries optimize household production by shifting non-market work to women. We believe this to still be a story of culture. However, our specifications with the full suite of controls aim to isolate cultural channels that are largely independent of labor force behavior.

A culture-based interpretation of our results is also consistent with married couples continuing non-market work allocation practices that were used before their migration. In fact, we find that male-female non-market work differences within OECD countries are highly correlated with the GGI. ${ }^{21}$ This suggests that immigrant time allocation behavior is likely reflective of what couples were doing before they migrated. To the extent this is the case, we believe this still to be a story of cultural transmission, since the source country characteristics continue to affect the migrants' behavior despite their US residence and exposure to the US environment and norms. However, based on past research, we think it is likely that culture has an effect on behavior independent of own behavior prior to migration. Specifically, Blau and Kahn (2015) found that immigrant women's labor supply in the United States was positively affected by source country female labor supply even after controlling for the immigrants' own labor force activity before migrating. This finding suggests a cultural influence beyond the immigrants'

\footnotetext{
${ }^{21}$ Specifically, we use data compiled by the OECD for countries in the OECD plus China and South Africa (we were unable to find such summary measures for other countries). The correlation between the GGI and the source country female-to-male non-market work ratio is -0.72 , and a simple regression of that ratio on the GGI returns a coefficient of -32.63 that is significant at the 0.001 level.
} 
actual pre-migration behavior for that variable and potentially for the variables we study here as well. $^{22}$

\section{Results}

\section{Differences in Time Allocation Across Immigrant Generations}

We first study the differences in time allocation across immigrant generations: natives, first-generation immigrants, and second-generation immigrants. (For simplicity, we use the term natives to refer to the third-plus generation.) To do this, we estimate Equation (1), which relates non-market work to immigrant status and a set of controls. The results from this analysis are presented in Table 2. The first three columns show the results for total non-market work with each panel showing the results for a different sample. Panel A includes all women, Panel B is restricted to women with at least one child under the age of 18, Panel $\mathrm{C}$ includes all men, and Panel D is restricted to men with at least one child under the age of 18 . The first column of each outcome reports results for the parsimonious regression of Equation (1), including controls for the respondent's age and race/ethnicity, as well as day of the week, month, year, and state fixed effects. The second column of each outcome adds controls for education, children, and spouse demographics, all detailed in the methods section above. This is our preferred specification. In Columns (3), (6), and (9), we add controls for wife's market work. As noted earlier, wife's market work time is determined jointly with non-market work; however, including it as a control is useful in descriptively tracing the mechanism through which source country culture can affect the allocation of non-market time and ascertaining whether differences in non-market work solely reflect differences in labor supply decisions. Compared to our preferred specification, the

\footnotetext{
${ }^{22}$ Blau and Kahn (2015) used the New Immigrant Survey, which contains information on individual migrants' premigration labor force activity. The CPS does not include such information.
} 
results indicate that differences in wife's market work account for only a small portion of the immigrant-native difference in total non-market work: about 29 percent for women and 9 percent for men.

Across all samples, immigrants are more traditional than natives, the reference group, with immigrant women doing significantly more total non-market work and immigrant men doing significantly less. This finding is robust across all specifications, including controlling for wife's market work in Column (3), and always statistically significant at the 1 percent level. Among women, restricting the sample to only those with children increases the magnitude of the immigrant effect. In Column (2) - our preferred specification - the immigrant effect on total non-market work is an additional 3.8 weekly hours compared to natives for all women, or an additional 5.1 weekly hours for immigrant women with children. These increases represent 14 and 15 percent of the respective female sample averages. For immigrant men, the effect is a decrease of 2.1 weekly hours for all men, or 1.8 hours for immigrant men with children. These represent 14 and 11 percent of the respective male sample means. Columns (4) through (9) repeat the analyses separately for housework and childcare, showing that the total non-market work difference is driven primarily by differences in time spent on housework, though there is a small and significant effect for childcare among women with children in our preferred childcare specification shown in Column (11), Panel B. ${ }^{23}$

Second-generation immigrants are much more similar to natives than they are to immigrants. While in the parsimonious specification there is some evidence of a significant effect in the expected direction for childcare, these effects are not statistically significant in our preferred specification, suggesting that they reflect the impact of differences in education and

\footnotetext{
${ }^{23}$ As noted, our definition of total non-market work includes some items not in housework or childcare, such as caring for others in the household. These amounted to a very small portion of total non-market work time.
} 
other variables between second generation immigrants and natives. Although not significant, the coefficient for second-generation women in the parsimonious specification is always in the expected (traditional) direction across all outcomes. Among second-generation men, the estimated coefficients are small and not statistically significant in every specification, with the exception of the effect on childcare in the parsimonious specifications, where we obtain significant "wrong signed" (positive) effects.

An additional set of findings from the regressions shown in Table 2 (results not shown) is that more highly educated women and men spend more time with children relative to less highly educated individuals, an effect consistent with previous research (Gauthier, Smeeding, and Furstenberg 2004; Guryan, Hurst, and Kearney 2008). Specifically, for respondents with children, the effect of having a bachelor's degree or more (compared to anything less) is 0.85 additional hours of childcare by women and 0.44 additional hours of childcare by men. Both effects are significant at the 1 percent level. ${ }^{24}$ The effect for women is especially noteworthy because the impact of a $\mathrm{BA}+$ on housework is significantly negative, as one might expect.

\section{The Effect of Source Country Characteristics on Immigrants}

Having established that immigrants are generally more traditional in their allocation of time to non-market work, we now turn to the role of source-country culture-measured through source country gender equity — on this relationship. While we continue to provide results that sequentially add additional control variables, as in Table 2, we again note that our preferred specification is that which includes children and spousal demographics controls. This specification includes the main determinants of time allocated to non-market activities but omits

\footnotetext{
${ }^{24}$ We also ran these regressions including indicators for less than high school, high school diploma, and some college, leaving BA+ as the omitted category. All of these coefficients were significant and negative with two exceptions: the some college coefficient was very slightly positive but highly insignificant for all men and negative but insignificant for men with children.
} 
the control for wife's market work, which we included to determine whether the results for nonmarket work persist even when taking into account the endogenously determined time spent in the market.

Table 3 shows the results of estimating Equation (2) for all female immigrants (Panel A) and female immigrants with at least one child under 18 (Panel B), with corresponding specifications presented for men in Table 4. The estimates in Table 3, Column (1) show that women from more gender equal countries do less total non-market work than women from less gender equal countries. This finding is robust to the addition of controls for children and spousal characteristics in (Column (2). When we further control for the respondent's market work hours in Column (3), the effect is still significantly negative for both all women and women with children, with the coefficients 43 percent as large as those in Column (2) for both samples. Thus, in an accounting sense, nearly 60 percent of the impact of source country gender equality on total non-market work operates through its effect on market work hours. However, even controlling for market work, immigrant women migrating from more gender-equal countries do considerably less total non-market work. The models for housework and childcare also show significantly negative effects of GGI. The absolute effect is larger for housework than for childcare, but the effects are quite similar relative to their respective sample means in our preferred specifications. Specifically, the ratio of the GGI coefficient to the respective mean is -1.11 for housework and -0.98 for childcare for all women. The results are similar when we restrict the sample to those with children (Table 3, Panel B), but the magnitude of the coefficients is somewhat larger. Moreover, the absolute effect of $G G I$ on housework continues to be larger than its effect on childcare hours for this group, and the effect relative to the mean is now also larger for housework than childcare (-1.33 for housework and -0.87 for childcare). 
Overall, Table 3 shows statistically significant and moderately large negative effects of source country gender equality on immigrant women's total non-market hours, housework hours, and childcare hours. These findings suggest a further impact of source country culture on immigrant behavior beyond that observed in previous studies that examined outcomes such as fertility, female labor supply, or son preference.

Table 4 presents analogous results for male immigrants. In just about every case, we find statistically significant positive effects of $G G I$ on men's total non-market work, housework, and childcare although the coefficients for total non-market work and housework are smaller in absolute value than they are for women in our preferred specification (not controlling for women's market work). That is, greater source country gender equality raises men's contributions to household production. This increase is smaller in magnitude than the decrease in women's hours for total non-market work and housework although, given men's smaller mean levels of non-market work and housework hours, percentage effects tend to be much larger for men than for women. These findings point to a role of cultural factors in influencing the nonmarket time allocation decisions of men as well as women.

To further assess the magnitude of the estimated effects of source country GGI, we compare Canada, with a GGI at the $90^{\text {th }}$ percentile of our sample's GGI distribution and a value of 0.72 , to India, at the $10^{\text {th }}$ percentile of our sample with a GGI of $0.60 .{ }^{25}$ Specifically, in Table 5 we calculate the effect on each dependent variable of changing GGI from India's to Canada's level, based on our preferred specification. For all female immigrants, we find a decrease in total non-market work of 4.3 hours per week (13 percent of the sample average); a decrease in housework of 3.0 hours per week (13 percent of the sample average); and a decrease in childcare

\footnotetext{
${ }^{25}$ These percentiles are computed using individual immigrant women as data points, weighted by sampling weights. Thus, larger sending countries implicitly receive larger weight in the calculations.
} 
of 1.0 hours per week (12 percent of the sample average). ${ }^{26}$ Thus, the magnitude of the effect of such a change in source country gender equality is noticeable and fairly similar across each dependent variable relative to its sample average. Results are similar for immigrant women with children, with effects relative to their means for total non-market work (14 percent) and housework (16 percent) only slightly larger than for all immigrant women and a proportional impact on childcare (10 percent) that is actually slightly smaller than for all immigrant women.

For men, Table 5 indicates that a change from India's to Canada's GGI value raises men's non-market work and housework by larger percentages than the corresponding reductions for women. Moreover, the effect of source country gender equality is especially noteworthy for men's childcare: the effect of a change from India's to Canada's GGI values raises the childcare hours of men with children 1.4 hours per week in our preferred specification, an effect that is statistically significant and almost identical in magnitude to the corresponding reduction found for women with children. This means that total parental time with children is approximately unchanged. Of course, relative to the average childcare hours for men with children, this impact is a much larger percentage than it is for women (a 25 percent increase for men vs. a 10 percent decrease for women).

These results indicate that greater source country gender equality lowers immigrant women's and raises immigrant men's total non-market work, housework and childcare. Combining these two effects implies that greater source country gender equality lowers the gender gap in non-market work, just as it does for market labor supply (Blau, Kahn, and Papps, 2011). This is shown explicitly in Table 5 in the columns labeled $W-M$ and

\footnotetext{
${ }^{26}$ Recall that our definition of total non-market work includes some activities not included in housework or childcare; therefore, the sum of the $G G I$ effects on housework and childcare need not be the same as the $G G I$ effect on total non-market time.
} 
$(W-M) /$ Mean Gap. Results are similar for all immigrant women and those with children considered separately. Raising the GGI from India's to Canada's level lowers women's hours and raises men's hours and therefore lowers the gender gap in hours. The decreases in the gender gap in non-market work range from 35 to 38 percent among all immigrants and from 37 to 40 percent for immigrants with children, and each effect is highly statistically significant. In absolute terms, the effect of higher source country GGI is larger for housework than for childcare. Specifically, going from the India to Canada GGI value leads to statistically significant reductions in the housework gender gap of 5.2 and 6.2 hours per week for immigrants with and without children, respectively, and reductions in the childcare gender gap of 1.8 and 2.7 hours per week for immigrants with and without children, respectively. However, relative to the average gender gap, the impacts are slightly larger for childcare than housework.

An additional set of results associated with Tables 3 and 4 concerns the changes in immigrant non-market work with additional time in the United States. Since the model includes own and spouse cohort dummy variables and we have independent cross-sections, we can interpret the years since migration (YSM) and partner YSM coefficients as measuring the impact of time in the United States relative to arrival (Borjas, 1985). ${ }^{27}$ Table A1 shows the results of simulations where we estimate the effect of years since arrival on non-market work time for immigrant couples who migrated together 10,20 or 30 years ago, relative to what would be observed on arrival. ${ }^{28}$ For immigrant women, total non-market work and housework decrease with time in the US, assimilating towards native levels. The effects are consistently negative, as

\footnotetext{
${ }^{27}$ Of course, like other analyses using independent cross-sections, our interpretation of the YSM coefficients must be qualified by admitting the possibility of selective return migration (Lubotsky 2007).

${ }^{28}$ These simulations are based on Columns (2), (5), and (8) of Tables 3 and 4. Namely, these specifications include controls for YSM and YSM-squared for both the respondent and the partner. The simulation results simply sum these four relevant coefficients scaled by the respective YSM or YSM-squared value. The same YSM value is used for the respondent and spouse. Standard errors are computed accordingly.
} 
one might expect with assimilation toward US norms, though only statistically significant for women with children. The point estimates for women's childcare are smaller than for housework in magnitude (both absolutely and relative to the mean) but are in the expected negative direction (i.e., consistent with childcare time decreasing with time in the US). For immigrant men, there is some evidence of total non-market work and housework decreasing in YSM and childcare increasing in YSM, though none of these effects are statistically significant.

The specifications in Tables 3 and 4 do not include the GGI of an immigrant's spouse (in the likely event that he/she is married to an immigrant). This means that the effects of own $G G I$ in these tables can be seen as a reduced-form effect for the immigrant's $G G I$, taking the spouse's $G G I$ as potentially endogenous. Specifically, it may be difficult to distinguish the effects of one's own GGI from that of spouse GGI for those married to immigrants, especially since many immigrants are married to someone from the same country of origin. In our sample, 80.6 percent of immigrant women and 82.9 percent of immigrant men had immigrant spouses, and of those immigrants with immigrant spouses, 86.9 percent of immigrant women and 87.0 percent of immigrant men were born in the same country as their spouse. Further, the correlation between own and partner GGI for immigrants with immigrant spouses is 0.89 . Nonetheless, it is potentially interesting to take account of the type of country the spouse comes from, beyond the controls for spouse immigrant and spouse second generation.

In Table 6, we explore the impact of spouse's GGI in a way that is meaningful given the high correlation between own and spouse GGI. The table shows the results of models restricted to immigrants married to immigrants and where we include the children and spouse control variables (i.e., the specifications of Columns (2), (5), and (8) of Tables 3 and 4). Because of the collinearity between own and spouse's $G G I$, we present the sum of the own and spouse $G G I$ 
coefficients, as well as the individual $G G I$ coefficients. The sum of one's own and one's spouse's $G G I$ effects can be seen as the result of comparing an immigrant couple that migrates together from a country with a higher value of $G G I$ to an otherwise similar couple migrating from a country with a lower value of GGI. Compared to the GGI coefficients in Tables 3 and 4 (where we did not control for spouse's GGI), the sums in Table 6 provide the effect of a stronger "treatment" of source country culture for spouses from countries with the same GGI. Looking first at women, the sum of the own and spouse $G G I$ effect is in each case slightly larger than the own GGI effect in Table 3, although the sum in Table 6 is not significantly different from the individual GGI coefficient in Table $3 .{ }^{29}$ For example, looking at all immigrant women, the sum of one's own and one's spouse's $G G I$ effects for total non-market work is -41.6 hours per week and is highly significant; the individual $G G I$ effect in Table 3 is -35.8 hours per week and is also highly significant. Thus, for women, there is some suggestive evidence that being married to someone coming from the same country provides a stronger treatment of source country culture.

For immigrant men, there is also some evidence of a stronger treatment effect for those married to immigrant women from a country with the same GGI than for the average immigrant man, but the evidence is weaker than it is for women. On the one hand, the sums of own and spouse GGI effects in Table 6, Panel B for all immigrant men married to immigrant women are slightly smaller compared to the own $G G I$ effects for all immigrant men in Table 4, suggesting no stronger treatment effect. On the other hand, the sums for immigrant men with children in Table 6 for total non-market work and housework are somewhat larger than the own $G G I$ effects

\footnotetext{
${ }^{29}$ The own GGI coefficients for women shown in Table 6 are much larger in magnitude than those for spouse's GGI for Total Non-Market Work and Housework, perhaps reflecting a stronger influence of one's own culture than one's spouse's culture; however, the effect of spouse's $G G I$ is larger than the own $G G I$ effect for childcare, perhaps reflecting the difficulty in distinguishing the two effects because of their collinearity.
} 
in Table 4, although not significantly so; the sum for childcare in Table 6, Panel D for men with children is, however, about the same size as the corresponding GGI coefficient in Table $4 .{ }^{30}$

\section{Possible Selection Biases}

The results presented so far suggest strong negative effects of source country gender equality on immigrant women's non-market work time and positive effects on immigrant men's non-market work time. We have interpreted such findings as indicating the role of source country culture as measured by the Gender Gap Index on immigrant behavior in the United States. However, it is possible that women migrating from higher GGI countries are relatively more market and less home oriented than the average for their country, while immigrant men from high GGI countries may be more home-oriented than average men from their countries. If so, then the effects of $G G I$ we have shown may simply be due to selection (i.e., who migrates) rather than a true effect of source country culture on immigrant behavior in the United States. This type of selection is somewhat more nuanced than typical immigration selection stories. For example, our results would not be biased simply because couples are induced to immigrate by economic opportunities for husbands, leading to a disproportionate share of non-market work falling on wives. It would instead have to be the case that the aforementioned behavior operated more extremely in low-GGI compared to high-GGI countries. Similarly, our results would not be biased simply if couples from low-GGI countries were induced to immigrate to the US for different reasons than couples from high-GGI countries, perhaps due to economy-wide shocks in low-GGI countries but personal reasons in high-GGI countries. Instead, motivators would have

\footnotetext{
${ }^{30}$ For men, the relative effects of own and spouse $G G I$ in Table 6 are unstable. For example, among all immigrant men (married to immigrant women), the effect of spouse GGI on housework is about equal to the effect of own GGI; however, for married men with children, the own effect is much larger. The results for men give us further reason to be careful about making strong conclusions about the relative impacts of own and spouse GGI given the high level of collinearity.
} 
to differ between countries in how they induced immigration for couples of various non-market work allocation inclinations. Differential visa status between husbands and wives would have to operate in the same way to bias our results.

We believe selection of the type outlined above is very unlikely to be driving our results, and that the estimated effects of $G G I$ at least in part reflect the transmission of culture. For one thing, the cost of immigration (psychic and assimilation costs) is likely to be lower in general for those with more similar tastes and skills to those of US natives. If this is the case, it would suggest that, to the extent selection plays a role, women who are most similar to US women would choose to migrate here. Thus, for example, the women migrating from low-GGI countries would be those most likely to be less traditional in their time allocation preferences compared to others in their source countries. This would dampen observed differences in the behavior of women from different source countries once living in the United States, causing a downward bias in the estimated effect of source country $G G I$ and making it harder to obtain our results.

Additionally, an effect of source country characteristics independent of possible selection bias is consistent with findings from Blau and Kahn (2015). Using data from the New Immigrant Survey, which has information on immigrants' work hours before migrating, they found that immigrant women's labor supply in the United States was positively affected by source country female labor supply, even after controlling for immigrant women's own labor force activity before migrating. Women from high female labor supply source countries (and therefore likely high GGI countries) who did not work before migrating are likely to be especially negatively selected for labor supply; yet source country female labor supply exerted a large positive impact on their labor supply in the United States, implying a strong effect of culture. Unfortunately, neither the New Immigrant Survey nor the ATUS have data on pre- 
migration non-market work for immigrants. However, if a cultural impact was important for labor supply, it is not unreasonable to believe it is also important for time allocation within the home.

\section{Second-Generation Immigrants}

While it is interesting to see the evidence that source country culture continues to influence immigrant behavior in the United States after migrating, another question relates to the persistence of such effects, not only over the immigrant's own time in the United States but also across generations. We are able to address this question because the CPS provides information on parents' birthplace. As noted above, while differences between the native born and second generation immigrants are not substantial in our Table 2 baseline regressions, this does not preclude variation within this group related to source country. This is what we seek to investigate here, focusing specifically on the effect of $G G I$.

As noted above, to match ATUS respondents to parent source country characteristics, we use mother's source country characteristics unless the mother was born in the United States or her source country characteristics are missing, in which case, we use the father's source country characteristics. As also discussed above, we use the source country characteristics of just one parent due to the high correlation between the birthplace of each parent for second-generation respondents with two foreign born parents and prioritize the mother's birthplace because mother's source country has been found to have larger effects on second-generation women's fertility and labor supply_-variables related to gender roles (Blau, Kahn, Liu and Papps, 2013). Results were similar, however, when we used father's source country characteristics when available. 
Table 7 shows the results from estimating Equation (2) for second-generation immigrants for our preferred specification, i.e., including controls for children and spouse characteristics, but not for the wife's market work. For all women and women with children (shown in Panels A and C), the estimated effects of parent GGI on total non-market work, housework, and childcare are negative, as they were for immigrant GGI in Table 3. However, they are generally much smaller in magnitude than for immigrants and are not statistically significant for any of the dependent variables. We note that the sample size of the second generation is much smaller than for that of immigrants, which may help to account for the lack of significance. Nonetheless, a reasonable conclusion is that the effect of parent country's GGI on time allocation for secondgeneration women is weaker than the impact of source country $G G I$ for immigrants, an outcome one might expect if women assimilate to US norms across generations.

The results for male second-generation immigrants (shown in Panels B and D) are actually stronger than those for women and constitute our most interesting finding for the second generation. Most noteworthy are the positive and statistically significant effects of parent $G G I$ on total non-market work and childcare for men with children. ${ }^{31}$ The childcare effects are even larger than they are for immigrant men. For all second-generation men, higher parent GGI has statistically insignificant negative effects on total non-market work and housework, but significant positive effects on childcare. These positive findings for childcare suggest cultural transmission of source country gender roles across generations particularly as they affect the time men devote to their children.

\section{Robustness Checks and Additional Analyses}

\section{Alternative Children Controls Accounting for Sex of Child}

\footnotetext{
31 These effects are almost identical and equally as significant when we control for the wife's market work.
} 
As detailed above, our preferred specification includes controls for children. Children are measured using continuous variables counting the number of children in each of three age ranges: 0-5, 6-12, and 13-17. These controls do not account for the gender composition of the children. In a comprehensive review, Lundberg (2005) points to fairly robust findings that, overall, fathers tend to spend more time with sons than daughters. In addition, recent research by Baker and Milligan (2016) finds that both mothers and fathers invest more time in teaching activities with girls, particularly young girls, while fathers spend more time in recreational and sports activities with boys as they age. This raises the question of whether our results for firstand second-generation immigrants would be affected were we to explicitly control for children's gender composition. To capture this age and gender differential, we use the same age ranges as in our main specification but separate boys and girls (\# girls 0-5, \# boys $0-5$, etc.). We test the sensitivity of our results to both alternative children controls that account for gender and the interaction of the Gender Gap Index with children's age and gender. The first set of results, available on request, shows that our estimates of the impact of $G G I$ for immigrants and secondgeneration immigrants - both men and women - are nearly identical when we control for the gender of children. We then investigate whether $G G I$ affects the relative childcare given to boys and girls but do not find evidence that this is the case.

\section{Relative Contributions of GGI Subindexes}

To examine whether some aspects of source country gender equality are more important than others, Table A2 reproduces our preferred GGI specification from Tables 3 and 4 but substitutes the total GGI variable with the four GGI subindexes: political equality, health equality, economic participation equality, and education equality. Before discussing the results, 
a note of caution is in order. Some of the components of the index are noticeably positively correlated, so attempting to break out the impact of the separate components may be difficult. ${ }^{32}$

The female specifications in Table A2 show that the education subindex is significantly negatively related to the three dependent variables and that the economic participation subindex is significantly negatively related to housework and nearly significantly negatively related to total non-market work. Thus, these two subindexes appear to drive our findings for the overall index for women. The male specifications show similar patterns, with the education and economic participation subindexes playing an important role in higher male non-market work, though the education subindex results are never significant. Interestingly, the health subindex was associated with large increases in non-market work for both men and women, with all of the effect seeming to operate through housework. The effect of the political subindex was largely indistinguishable from zero for both men and women.

\section{Immigrant Age at Arrival}

One may suspect that immigrants arriving in the United States as children would be less susceptible to source country gender norms. Thus, including immigrants that arrived as children may understate the full transmission of source country culture. To explore this hypothesis, we examine whether our main results become stronger after dropping immigrants that arrived before age 18 - a restriction that drops about 27 percent of the immigrant sample. These results are available in full upon request. For female immigrants, the sample restriction leads to results that are slightly stronger but nearly indistinguishable from the main specifications in Table 3 . However, for male immigrants, dropping immigrants who arrived as children results in more

\footnotetext{
${ }^{32}$ In particular, the correlation coefficients are relatively high for the following: Health-Education (0.59), EconomicEducation (0.33), and Political-Economic (0.21); but less so for the following: Political-Health (-0.07), PoliticalEducation (-0.07), and Health-Economic (0.03).
} 
substantial increases in the GGI coefficients in several of the specifications from Table 4. For example, in our preferred specifications, the $G G I$ coefficient for total non-market work increased from 26.10 to 32.49 and the coefficient on childcare increased from 6.39 to 8.70. Thus, for men, migrating as an adult does appear to impart a larger "dose" of source country culture than migrating as a child, although it should be acknowledged that the differences between the corresponding coefficients are not significant.

\section{The Impact of Gender Norms About Relative Income}

We next explore how our findings relate to recent research on the gender norm that women should not outearn their husbands, or that the husband should be the primary breadwinner. Specifically, Bertrand, Kamenica, and Pan (2015), henceforth BKP, found evidence suggesting that US women who outearn their husbands increase their non-market work time as a way to compensate for violating this gender norm in market work. BKP find evidence of this phenomenon cross-sectionally and within couples. ${ }^{33}$ They also cite a large discontinuity in the distribution of the wife's relative income at the point at which the wife would earn more than her husband, suggesting that women alter their labor market choices to avoid violating the male breadwinner norm.

We extend the BKP analysis relating to this non-market work compensation, specifically looking at how the "penalty" differs between immigrants and natives and whether source country gender inequality affects the size of the penalty. We further examine how parent source country gender inequality may affect the penalty for second-generation immigrant wives. Our findings above show that immigrant women generally do more non-market work than native women and that source country inequality exacerbates this difference. Hence, we hypothesize that the non-

\footnotetext{
${ }^{33}$ Similar to us, their cross-sectional analysis uses the ATUS.
} 
market work penalty paid by immigrant women who outearn their husbands will be higher than that of natives and that the penalty will be exacerbated by source country gender inequality. In addition, we study whether men receive any compensating benefit in the form of lower nonmarket work time if their wives outearn them.

To examine these issues, we follow BKP by defining an indicator variable for couples in which the wife earns more than the husband (Wife Earns More) and then regressing non-market work on this indicator and a host of control variables. ${ }^{34}$ We extend the analysis by including source country characteristics, including $G G I$, as well as an interaction between Wife Earns More and GGI. However, to benchmark our main results, we first run a simpler specification that does not include source country characteristics, estimated for the entire sample and then separately for natives, immigrants, and second-generation immigrants. That is, we estimate the following regression, which is very similar to one used by BKP, separately for women and men: (3) $Y_{\text {idmys }}=\alpha_{0}+\alpha_{1}$ Wife Earns More E $_{i}+\alpha_{2}$ Relative Earnings $s_{i}+\alpha_{3} X_{i}+g_{d}+h_{m}+$ $j_{y}+k_{s}+v_{i d m y s}$

where the subscripts are defined as above and $Y$ is weekly total non-market work, also as defined above. For this analysis, in the interest of brevity, we focus on the overall effect for total nonmarket work, but mention results using childcare and housework as separate outcomes when interesting. Relative Earnings equals the wife's earnings divided by the sum of husband's and

\footnotetext{
${ }^{34} \mathrm{We}$ continue to use our sample restrictions and control variables from above whenever applicable. With the exception of our use of more recent years of data, the BKP sample restrictions were nearly identical to ours. Two small differences to note: they include 65 year olds, while we drop those older than 64, and we drop diary entries from holidays, while they do not. BKP also define their non-market work variable slightly differently than we do and use a slightly different set of control variables and fixed effects. Notably, our definition of non-market work differs due to our inclusion of care for household and non-household adults and our exclusion of non-grocery shopping, obtaining professional services, and travel related to shopping or obtaining services. We believe that adult care is non-market "work," while shopping and obtaining professional services could in many cases be considered self-care or leisure. Finally, BKP do not run separate male and female regressions, but instead interact all variables with a sex indicator variable. Our results are broadly similar when we adhere to the BKP sample and variable definitions as closely as possible.
} 
wife's earnings. Wife Earns More is a dummy variable equal to one if Relative Earnings is strictly greater than 0.5 . Our parameter of interest is the coefficient on Wife Earns More $\left(\alpha_{1}\right)$. A vector of controls $X_{i}$ includes a cubic in the log of wife's and husband's earnings; log of the total household income; and, as defined in Section IV, controls for both spouse's race/ethnicity, education, and age, as well as controls for number and ages of children. For our specification that focuses on immigrants, $X_{i}$ also includes controls for immigration cohort and years since arrival, as well as partner immigration status, years since migration, and immigration cohort, all as defined in Section IV. For our specification that focuses on second-generation immigrants, we of course omit the own immigration-related controls but include the spousal immigrationrelated controls. As above, the regressions also include day, month, year, and state fixed effects $\left(g_{d}, h_{m}, j_{y}\right.$, and $\left.k_{s}\right)$. See the Data Appendix for more discussion on variable construction.

To incorporate source country characteristics, we then estimate the following regression — again, separately for men and women — for first- or second-generation immigrants: (4) $Y_{\text {idmys }}=\theta_{0}+\theta_{1}$ Wife Earns More $_{i}+\theta_{2}$ Relative Earnings $_{i}+\theta_{3} G_{G} I_{i}+$ $\theta_{4}\left(\right.$ Wife Earns More $\left._{i} * G G I_{i}\right)+\theta_{5} Z_{i}+l_{d}+n_{m}+p_{y}+q_{s}+v_{i d m y s}$ where again, the subscripts have been defined above and $Y$ is weekly total non-market work. Now, our parameters of interest are the coefficients on Wife Earns More $\left(\theta_{1}\right), G G I\left(\theta_{3}\right)$, and their interaction $\left(\theta_{4}\right)$. For second-generation immigrants, we use parent source country characteristics, including GGI, as defined above. Here, the vector of control variables $Z_{i}$ includes all the variables from $X_{i}$ above in addition to controls for source country (or parent source country for second-generation immigrants) GDP and fertility. Fixed effects also correspond to those used in the above specification. 
Note that for both regressions, the specifications are somewhat similar to a regression discontinuity design (RDD), with Relative Earnings serving as the running variable. However, in this context, there may be non-random sorting on either side of the 50 percent relative earnings threshold. Nonetheless, exploring how non-market work changes for women and men when the wife chooses to cross this relative earnings threshold is interesting for immigrants and natives alike. Also of note, the inclusion of the cubic in log earnings for both the ATUS respondent and the spouse help give Relative Earnings a somewhat flexible functional form, but makes the coefficient on Relative Earnings difficult to interpret. For this reason, we focus on the Wife Earns More coefficients and their interaction with the GGI. All regressions are weighted using ATUS sampling weights adjusted so that each year receives the same weight. For the immigrant and second-generation immigrant regressions, we cluster all standard errors at the birthplace and parent birthplace level, respectively.

The results of estimating Equations (3) and (4) are shown in Table 8 for women and in Table 9 for men. Column (1) of each table shows results for Equation (3), while in Column (2), we estimate Equation (4) for the sample of first- and second-generation immigrants but omit the interaction of GGI and Wife Earns More. In Column (3) we add the interaction.

We reproduce the central BKP finding of a penalty for wives who outearn their husbands, with results shown in Panel A of Table 8. We find that these women do about 1.9 more hours per week of non-market work compared to those who earn the same or less than their spouses; this result is highly significant at the 1 percent level. ${ }^{35}$ This coefficient is similar to but somewhat smaller than that found by BKP, who estimate that women spend approximately 2.3 to

\footnotetext{
${ }^{35}$ Running the regressions separately for housework and childcare suggests that roughly two-thirds of the magnitude of the effect operates through housework and roughly one-third operates through childcare. Both regressions return a significant coefficient on Wife Earns More.
} 
3 hours more per week of non-market work when they earn more than their husbands. Panel B restricts the sample to native women, corresponding to the third-plus generation. The results here are similar to those for all women, though slightly smaller, which is not surprising, as natives make up the majority of that sample. On the other hand, immigrant women who outearn their husbands pay a significant and much larger penalty compared to their native counterparts, as seen in Panel C. Specifically, Column (1) shows a highly significant coefficient on Wife Earns More of 4.5 additional hours of non-market per week, and the effect is significantly greater than the corresponding native effect at the 5\% level. The results for second-generation immigrants are also positive, but not significant and slightly smaller than those for natives. As in the case of BKP, this set of results runs counter to Becker (1981), which would predict that as the wife's earnings make up a larger portion of total household earnings, her comparative advantage for household production likely falls and she spends fewer hours per week on non-market work. ${ }^{36}$

The point estimates discussed above suggest that the norm against wives outearning husbands is stronger for immigrants overall than for natives, consistent with our results in Table 2, as well as other research (e.g., Blau, Kahn and Papps 2011), which suggest that immigrants have a more traditional division of labor by gender than natives. However, if there are relatively fewer immigrant wives earning more than their husbands, there might be a concern that outliers are driving this result. This is unlikely, however, because the proportion of wives who earn more than their husband is fairly similar for immigrants and natives. About 27 percent of native wives

\footnotetext{
${ }^{36}$ Comparative advantage depends on each partner's value of non-market time relative to market time compared to the other partner. Thus, the expectation in the text implicitly assumes that the increase in the relative value of wife's market time is not offset by a comparable rise in the value of her non-market time.
} 
earn more than their husbands, while this is true of about 20 percent of first-generation immigrant wives and 27 percent of second-generation.

Columns (2) and (3) of Table 8 show the results associated with Equation (4). Adding GGI and other source country controls in Column (2) very slightly lowers the coefficient on Wife Earns More, but it remains highly significant. The coefficient on GGI is not statistically significant, but in the expected negative direction. ${ }^{37}$ In Column (3), we show the key interaction effects between $G G I$ and the indicator for whether the wife earns more. In both cases, the interaction effect has the "wrong" sign (it is positive) but is insignificant. Thus, while we find that immigrant women face a higher penalty as a result of outearning their husbands, we do not find evidence that this behavior varies significantly with the degree of source country gender equality. For second-generation women, we also find positive but insignificant coefficients on the interaction between parent GGI and Wife Earns More.

Table 9 shows the effect of the wife earning more for men's non-market work. Given the penalty found above for wives who cross the 50 percent relative earnings threshold, we might expect some of their increased non-market work to substitute for work that would otherwise be done by the husband. This would imply a negative coefficient on Wife Earns More for men. However, our estimates for Equation (3) - shown in Column (1) of Table 9-suggest that this is not the case. The estimated effects are never close to significance and the coefficient is slightly positive in all but one instance (second generation men, for whom the effect of Wife Earns More is insignificantly negative). ${ }^{38}$

37 The result for GGI in Table 8, Column (2) for immigrants contrasts with the much larger, statistically significant effect of this variable in our main model shown in Table 3. This is likely due to the additional controls included in Table 8, including wife's and husband income, wife's relative income, and whether the wife earns more than her husband - controls that are likely to be affected by GGI.

${ }^{38}$ However, when we estimate the regression using childcare as the outcome, we do find that immigrant men do 1.2 fewer hours of work when their wives earn more, significant at the 5 percent level. 
Columns (2) and (3) in Panels C and D of Table 9, which correspond to our estimates for Equation (4), show results of introducing source country characteristics (or parent source country characteristics for second-generation immigrants). In contrast to the results for women, we do find some evidence for immigrant men that more gender equity in the source country affects men's housework time in the expected direction. In Column (2), which omits the interaction of GGI and Wife Earns More, the coefficient on GGI for immigrants is significant and in the expected positive direction. Most interestingly, in Column (3) we find a significantly negative main effect of wives earning more and a significantly positive interaction effect between wives earning more and source country GGI. In other words, source country equality may indeed be an important mitigating factor in the otherwise negative effect of Wife Earns More on men's nonmarket work. When we explore this result using housework and childcare as separate outcomes, we find that this interaction effect is driven entirely by housework. While we do obtain some suggestive findings for immigrants, the corresponding results for second-generation men are not significant.

To aid interpretation of the role of GGI on the wife earning more effect for immigrant men's non-market work, we calculated the predicted effects evaluated at a low level of $G G I$ (India's 0.60) and a high level (Canada's 0.72) for the specification used in Column (3), Panel C of Table 9. Our results suggest that at a low level of GGI, men who are outearned by their wives do significantly less non-market work than otherwise, seemingly reaping a benefit from the violation of the gender norm; however at higher levels of $G G I$, there is no evidence that men do less non-market work when their wives cross the 50 percent relative earnings threshold. Specifically, we found that at India's GGI level, the effect of the wife earning more for men is a 
significant 3.2 fewer hours of non-market, but at Canada's level, a wife earning more is associated with an insignificant 2.2 hour increase in non-market work.

A concern that has been raised with respect to analyses like the one above is that wives may systematically underreport earnings and husbands may systematically overstate their earnings so as not to violate the gender norm of husbands outearning their wives. For this reason, some women with a computed relative earnings ratio below 0.5 may actually outearn their husbands. Murray-Close and Heggeness (2018) find evidence of this by comparing CPS reported earnings with administrative earnings records from the Social Security Administration. Specifically, in their primary specification they find that when a wife earns more than her husband, the wife's reported earnings are 1.5 percentage points lower than her administrative earnings and the husband's reported earnings are 2.9 percentage points higher than his administrative earnings. This suggests that households with a wife that just outearns her husband would on average have reported relative earnings of 0.489 , though it is likely that some women in the 0.489 to 0.5 range are accurately reporting that their husbands have higher earnings. Further, other authors have pointed out that rounding, heaping, and other reporting problems have led to a mass point of couples with artificially identical reported earnings. ${ }^{39}$ Given the similarities between the above regressions to RDD, this could bias the composition of the "control group" just to the left of the threshold. In light of the aforementioned findings, we reproduce our BKP-style regressions from Tables 8 and 9 while dropping all observations with relative earnings between 0.489 and 0.50 , inclusive. All our main findings are robust to this

\footnotetext{
${ }^{39}$ Binder and Lam (2019) find that artificial features of earnings reporting — such as top-coding, rounding, and imputation - create a large mass point of couples with identical reported earnings. Relatedly, Zinovyeva and Tverdostup (2018) show that family businesses and co-working of spouses can contribute to a mass point of couples with identical reported earnings. We were able to reproduce this mass point in our data set.
} 
specification. These results are shown in full in Tables A3 and A4, which correspond to Tables 8 and 9 , respectively.

Overall, we find evidence that the non-market work penalty faced by wives who earn more than their husbands is stronger for immigrants than natives although we do not find evidence that the size of the penalty varies with source country gender equality. However, there is some suggestive evidence that men coming from a culture with a lower level of gender equality will reap the benefit of their wives' violation of the gender norm by doing less nonmarket work, whereas men coming from countries with a higher level of gender equality do not.

\section{Conclusion}

Despite increasing female labor force participation prior to the 1990s and decreases in the gender wage gap dating from the 1980s, the gender gap in non-market work remains large and persistent. Although there has been some convergence, women still spend considerably more hours on housework than men, even if they are employed. This persistence in the gender differences in the allocation of time within the home likely contributes to gender differences in labor market outcomes. In contemplating how this division of labor may change, one question is whether it is malleable in the face of broader cultural factors. We address this question by using the American Time Use Survey to estimate the impact of source country culture on the gender division of household labor among US immigrants. One contribution of this paper is to study the impact of source country culture among men as well as women.

Overall, we find that immigrants have a more traditional division of labor than natives in that, even controlling for their characteristics, immigrant women tend to allocate more time to non-market work than their native counterparts, while immigrant men tend to allocate less. Using the Gender Gap Index from the World Economic Forum as an indicator, we find that 
source country gender norms do affect this division of household labor-influencing the time allocation decisions of men as well as women. Women from more gender equal countries spend fewer hours per week on household labor than their counterparts from less gender equal countries, allocating less time to both housework and childcare. Men from more gender equal countries spend more hours per week on non-market work compared to men from less gender equal countries, both for housework and childcare.

To further examine the impact of culture, as well as to gauge the extent of assimilation across immigrant generations, we look at second-generation immigrants. Based on descriptive statistics, we find that the total non-market work and housework of second-generation women and men are much more similar to natives with native parents than they are to immigrants, suggesting some intergenerational assimilation. In terms of the impact of parental source country gender equality, while we find no significant effect on the non-market work, housework or childcare of second-generation women, we do find effects for second-generation fathers. Specifically, we find that those from more gender egalitarian countries spend significantly more time on non-market work and childcare.

Finally, we study the impact of source country culture on the strength of the traditional norm that men are the primary breadwinners and should outearn women. Specifically, previous research has found that women who violate this norm pay a penalty by doing more housework (Bertrand, Kamenica and Pan, 2015). While we find that this norm holds on average in our data for both immigrants and native women, the penalty is larger for immigrants, consistent with immigrants being a more traditional group in terms of gender norms. However, the size of the penalty among immigrant women does not vary significantly with source country gender equity. For men, while we find no evidence of a significant effect of wives earning more on non-market 
work overall, immigrant men coming from a culture with a lower level of gender equality do appear to reap the benefit of their wives' violation of the gender norm by doing less housework, whereas this is not the case for men from more gender equitable source countries. 


\section{Theory Appendix}

Consider a stylized framework where a husband and wife each have $t_{g} \in[0,1]$ units of time to allocate toward market production and $1-t_{g}$ units to allocate toward non-market production, for $g \in\{m, f\}$. The household has a joint utility function that is increasing and concave in total market good consumption $c$ and household good consumption $b$. Utility also depends additively on a convex gender norm function $\pi\left(t_{f}, t_{m}\right)$ that penalizes the wife's market work relative to the husband's market work. Market goods can be purchased with wages earned from market work, while household goods are produced via non-market production. The husband and wife can differ in their exogenous wage rate $w_{g}$ and productivity in home production.

Couples maximize utility subject to a market good consumption (income) constraint and their household non-market goods production function. Before putting any more structure on the model, note two main general results. First, couples will optimize their time at the point when the marginal utility gain from market work is equal to the marginal utility gain of non-market work. Second, the wife's market work will decrease in the magnitude of the gender norm (and hence her non-market work will increase), while the husband's market work will increase in the magnitude of the gender norm (and hence his non-market work will decrease). In the absence of income effects, market work will increase in the wage rate and non-market work will increase in home productivity for both men and women.

To see this in a concrete example, we assume that households solve the following maximization problem, where utility is additively separable with a linear gender norm penalty and a CobbDouglas household production function:

$$
\begin{gathered}
\max _{t_{m}, t_{f}} c+\varphi \log b-\pi\left(t_{f}-t_{m}\right) \\
\quad \text { s.t. } c=w_{m} t_{m}+w_{f} t_{f} \\
b=A\left(1-t_{m}\right)^{\alpha}\left(1-t_{f}\right)^{1-\alpha}
\end{gathered}
$$

where $\alpha \in(0,1)$ is the relative productivity of the husband in household good production and $\pi$ is a positive scalar. First order conditions yield the following solution for optimal non-market work time:

$$
\begin{aligned}
& 1-t_{f}^{*}=\frac{\varphi(1-\alpha)}{w_{f}-\pi} \\
& 1-t_{m}^{*}=\frac{\varphi \alpha}{w_{m}+\pi}
\end{aligned}
$$

The general conclusions from above may be seen explicitly in these first order conditions. That is, non-market work is increasing in $\pi$ for women and decreasing in $\pi$ for men. Further, since this model does not have income effects, non-market work is increasing in relative productivity and decreasing in the wage rate for both men and women. For market work, the converse holds. Note that specific parameterizations must be checked for corner solutions (namely, if the penalty is too large, the wife will spend all her time in home production). 
This framework can easily accommodate modeling the wage rate as an endogenous function of the gender norm penalty. For example, we may imagine the gender norm representing a general attitude about women's accumulation of human capital and thus a stronger penalty decreases her market productivity and hence her wage rate. In this case, the first order conditions for optimization remain the same, though we need to explicitly note the dependence of the wife's wage on $\pi$ for the comparative statics with respect to the penalty. If we assume that the wife's wage decreases in the gender norm, the direction of the effect on non-market allocation is the exact same but with a stronger magnitude.

While the theoretical model considers wages, our empirical work is reduced form with respect to wages in order to avoid well-known problems of estimating (imputing) a wage rate for labor force nonparticipants. This makes it important to control for variables related to human capital to isolate the effect of the penalty. However, the model discussed in this preceding paragraph suggests that those variables are themselves endogenous, motivating our empirical strategy of testing the effect of source country gender norms with and without the inclusion of human capital controls such as age and education. 


\section{Data Appendix}

\section{Variable Definitions}

\section{A. Demographic Variables from the ATUS and CPS}

\section{Race and Ethnicity}

- We control for race and ethnicity using a set of indicator variables for five mutuallyexclusive categories: White non-Hispanic, Black non-Hispanic, Asian non-Hispanic, other non-Hispanic, and Hispanic.

- Respondent is classified as Hispanic if the respondent reports being Hispanic or reports his/her ethnicity as Spanish, Portuguese, Mexican, Puerto Rican, Latin American Indian, South American Indian, or Mexican American Indian.

- Respondent is classified as black non-Hispanic if the respondent reports being any detailed race that includes black and is not classified as Hispanic.

- Respondent is classified as Asian non-Hispanic if the respondent is not classified as Hispanic or black non-Hispanic and reports race as Asian or any mixed race including Asian.

- Respondent is classified as white non-Hispanic if the respondent is not classified as Hispanic, black non-Hispanic, or Asian non-Hispanic and reports race as white.

- Respondent is classified as other non-Hispanic if none of the above classifications apply.

\section{First- and Second-Generation Immigration Variables}

- Respondents are classified as first generation if they report their birthplace as outside the 50 states or the District of Columbia. Note that we count respondents born in US territories as immigrants, though they are not included in most immigrant analyses due to not having independent source country characteristics.

- Respondents are classified as second generation if they were born in the fifty states or the District of Columbia and they report that either of their parents was born outside the United States.

- Second-generation immigrant respondents are assigned the source country characteristics of their mother unless their mother's source country characteristics are missing or their mother is US born. In that case, they are assigned their father's source country characteristics. We follow this procedure because the high correlation between father's and mother's birthplace when both are foreign born makes estimating separate effects of father's and mother's source country difficult in a sample of this size. (Of second-generation immigrants where both parents are foreign born, both parents are from the same source country for 87.2 percent of our sample.) We compare our results to those that prioritize father source country characteristics and find them to be similar.

- We use the term native to refer to those who were born in the United States, with both parents born in the US. That is, natives may be considered third-plus-generation immigrants. 
- We compute years since migration as the difference between the survey year and the midpoint of the binned response to year of immigration. The mid-point of the binned response to year of immigration is also used to assign immigration cohorts.

\section{Earnings Variables in Section VII}

- We set earnings to 0 for those reporting to be unemployed or out of the labor force. We set earnings to missing if reported earnings are outside the ATUS defined range. We inflate top-coded earnings by 1.5. According to IPUMS: "[The individual earnings variable] was collected at the time of the ATUS interview. However, earnings information was only collected at that time for respondents who changed jobs or employers since the final CPS interview, or whose earnings were allocated in the final CPS interview. For other respondents, earnings information was carried forward from the final CPS interview" (https://www.atusdata.org/atusaction/variables/EARNWEEK\#description_section). Further, spousal earnings are not updated at the time of the ATUS interview, but are always carried forward from the final CPS interview. The final CPS interview takes place two to five months before the ATUS interview.

- Our measure of total household income comes from the CPS family income variable, which includes earned and unearned income of all household members. This variable is not updated at the time of the ATUS interview. Family income is reported in ranges, and we use the mid-point of reporting bins.

- We set log earnings to zero for those with 0 earnings.

- Relative earnings are defined as the wife's earnings divided by the sum of the husband's and wife's earnings. If only one spouse is employed, relative earnings are set to 1 or 0 accordingly.

\section{B. Country Characteristics Variables}

\section{Total Fertility}

- Total fertility data come from the World Bank, available at http://data.worldbank.org/indicator/SP.DYN.TFRT.IN. In the regressions with country characteristics, we include 2000-2007 country averages of total fertility.

\section{GDP Per Capita}

- Most GDP per capita data come from the World Bank, available at http://data.worldbank.org/indicator/NY.GDP.PCAP.PP.KD. GDP for Argentina, Burma (Myanmar), and Syria is constructed from UN Stats data on GDP by Type of Expenditure at current prices and at constant 2005 prices in national currency units, available at http://data.un.org/Data.aspx?d=SNAAMA\&f=grID $\% 3 A 101 \% 3$ BcurrID $\% 3 A N C U \% 3 B p c$ Flag $\% 3 \mathrm{~A} 0$ and http://data.un.org/Data.aspx? $\mathrm{q}=\mathrm{gdp} \& \mathrm{~d}=\mathrm{SNAAMA} \& \mathrm{f}=\mathrm{grID} \% 3 \mathrm{a} 102 \% 3 \mathrm{bcurrID} \% 3 \mathrm{aNCU}$ $\% 3 \mathrm{bpcFlag} \% 3 \mathrm{a} 0$, respectively. PPP conversion rates come from http://icp.worldbank.org/icp/QueryResults.aspx? $r=-1 \& d s=0 \& y=3 \& w s=1$. We use the World Bank methodology to convert to GDP per capita, PPP. 


\section{Global Gender Gap Index}

- The index of gender equality comes from the World Economic Forum's "The Global Gender Gap Report." In the regressions with country characteristics, we include 20062007 country averages of the index, unless a 2006 value is not available, in which case we use the earliest value available up until 2012. The 2006 and 2007 reports are available at http://www3.weforum.org/docs/WEF_GenderGap_Report_2006.pdf and http://www3.weforum.org/docs/WEF_GenderGap_Report 2007.pdf.

\section{ATUS Variables}

We define housework as all activities that fall under the broad ATUS "Household Activities" category. These include housework, food and drink preparation and cleanup, home maintenance, lawn and garden care, pet care, appliance care, and household administrative tasks. We define primary childcare as care for children living in the household, including the "second-tier" ATUS categories of "Caring for \& Helping HH Children," "Activities Related to HH Children's Education," and "Activities Related to HH Children's Health." We define total non-market work as the sum of these housework and childcare variables, as well as time spent grocery shopping and all the activities included in the "second-tier" ATUS categories of "Caring for Household Adults," "Helping Household Adults," and "Caring for \& Helping NonHH Members."

\section{Sample Selection}

We use data from the 2003-2017 waves of the American Time Use Survey (ATUS). For the main analysis, we focus on first- and second-generation immigrants as defined above. When natives are included, they are defined as those who are born in the United States with both parents born in the US. Regressions are weighted by ATUS sampling weights that are normalized to provide equal weighting for each sample year.

We restrict our sample to married respondents in heterosexual partnerships where both the respondent and their spouse are between the ages of 18 and 64. To do this, we keep only respondents who report being married with a spouse present in the household. To collect partner characteristics, we match these respondents to the member of their respective households who lists the respondent as a spouse. If no household member lists the respondent as a spouse, we match the respondent to the member of the household who lists the respondent as an unmarried partner. We then drop any remaining respondents who do not match. We also exclude observations recorded on holidays, natives born abroad, and immigrants whose year of immigration is missing. While we are not able to observe the time allocation of the respondent and their partner, by enforcing these restrictions, we can estimate for the population how married men and women divide household labor. All analyses were repeated including those in heterosexual partnerships but not married. To do this, we do not impose the initial restriction of keeping only respondents claiming to be married with a spouse present. We follow the same 
partner match procedure outlined above. Our results are similar when partnered respondents are included (results available on request).

In some regressions, the sample is implicitly restricted due to missing data on control variables. Regressions that control for a range of spousal characteristics resulted in a few dropped observations that had missing values for any of these characteristics. Further, some immigrants did not match to source country characteristics and are therefore dropped from regressions including these characteristics. Namely, some source countries do not have GGI scores available, a list that includes any US territory, Taiwan, Haiti, Iraq, Hong Kong, and Laos.

We also recoded the source country of some immigrants to make matching possible. This included assigning individuals from England, Scotland, Wales, and Northern Ireland to the source country characteristics of the UK; assigning individuals from Azores to Portugal; assigning individuals from Kosovo to Albania; assigning individuals from Palestine to Israel; and assigning individuals from "USSR, n.s." to Russia. 


\section{References}

Antecol, Heather. 2000. "An Examination of Cross-Country Differences in the Gender Gap in Labor Force Participation Rates," Labour Economics 7 (July): 409-426.

Baker, Michael and Kevin Milligan. 2016. "Boy-Girl Differences in Parental Time Investments: Evidence from Three Countries." Journal of Human Capital 10 (Winter): 399-441.

Becker, Gary S. 1965. "A Theory of the Allocation of Time.” Economic Journal 75 (September): 493-517.

Becker, Gary S. 1981. Treatise on the Family. (Cambridge: Harvard University Press; Enlarged edition, 1991).

Becker, Gary S. 1985. "Human Capital, Effort, and the Sexual Division of Labor." Journal of Labor Economics 3 (January, Part 2): S33-58.

Bertrand, Marianne, Emir Kamenica, and Jessica Pan. 2015. "Gender Identity and Relative Income Within Households.” Quarterly Journal of Economics 130 (May): 571-614.

Bianchi, Suzanne M., Melissa A. Milkie, Liana C. Sayer, and John P. Robinson. 2000. "Is Anyone Doing the Housework? Trends in the Gender Division of Household Labor." Social Forces 79 (September): 191-228.

Bianchi, Suzanne M., Melissa A. Milkie, Liana C. Sayer, and John P. Robinson. 2012. "Housework: Who Did, Does, or Will Do It, and How Much Does It Matter?" Social Forces 91 (September): 55-63.

Binder, Ariel J. and David Lam. 2019. "Is There a Male Breadwinner Norm? The Hazards of Inferring Preferences from Marriage Market Outcomes." NBER Working Paper 24907.

Blau, Francine D. 1992. "The Fertility of Immigrant Women: Evidence from High-Fertility Source Countries," in George J. Borjas and Richard B. Freeman, eds., Immigration and the Work Force: Economic Consequences for the United States and Source Areas (Chicago, IL: University of Chicago Press), pp. 93-133.

Blau, Francine D. and Lawrence M. Kahn. 2007. "Changes in the Labor Supply Behavior of Married Women: 1980-2000.” Journal of Labor Economics 25 (July): 393-438.

Blau, Francine D. and Lawrence M. Kahn. 2015. "Substitution between Individual and Source Country Characteristics: Social Capital, Culture, and US Labor Market Outcomes among Immigrant Women.” Journal of Human Capital 9 (Winter): 439-482.

Blau, Francine D., Lawrence M. Kahn, Peter Brummund, Jason Cook, and Miriam LarsonKoester. Forthcoming. "Is There Still Son Preference in the United States?" Journal of Population Economics, DOI: https://doi.org/10.1007/s00148-019-00760-7.

Blau, Francine D., Lawrence M. Kahn, Albert Yung-Hsu Liu, and Kerry L. Papps. 2013. “The Transmission of Women's Fertility, Human Capital, and Work Orientation Across Immigrant Generations." Journal of Population Economics 26 (April): 405-435. 
Blau, Francine D., Lawrence M. Kahn and Kerry L. Papps. 2011. "Gender, Source Country Characteristics and Labor Market Assimilation Among Immigrants: 1980-2000." Review of Economics and Statistics 93 (February): 43-58.

Blau, Francine D. and Anne E. Winkler. 2018. The Economics of Women, Men, and Work, $8^{\text {th }}$ ed. New York: Oxford University Press.

Borjas, George J. 1985. "Assimilation, Changes in Cohort Quality, and the Earnings of Immigrants." Journal of Labor Economics 3 (October): 463-489.

Bredtmann, Julia and Sebastian Otten. 2013. "The Role of Source- and Host-Country Characteristics in Female Immigrant Labor Supply.” Munich Personal RePEc Paper No. 44544.

Burda, Michael, Daniel Hamermesh, and Philippe Weil. 2013. "Total Work and Gender: Facts and Possible Explanations.” Journal of Population Economics 26 (January): 239-261.

Bütikofer, Aline, Katrine V. Løken, and Alexander Willén. 2019. "Building Bridges and Widening Gaps: Efficiency Gains and Equity Concerns of Labor Market Expansions.” NHH Discussion Paper 19/2019.

Campbell, Colin and Jonathan Horowitz. 2016. "Does College Influence Sociopolitical Attitudes?" Sociology of Education 89 (January): 40-58.

Coltrane, Scott. 2000. "Research on Household Labor: Modeling and Measuring the Social Embeddedness of Routine Family Work." Journal of Marriage and the Family 62 (November): 1208-1233.

Correll, Shelley J., Stephen Benard, and In Paik. 2007. "Getting a Job: Is There a Motherhood Penalty?" American Journal of Sociology 112 (March): 1297-338.

Cunningham, Mick. 2008. "Changing Attitudes toward the Male Breadwinner, Female Homemaker Family Model: Influences of Women's Employment and Education over the Lifecourse." Social Forces 87 (September): 299-323.

Davis, Shannon N., and Theodore N. Greenstein. 2009. "Gender Ideology: Components, Predictors, and Consequences." Annual Review of Sociology 35: 87-105.

Fernández, Raquel, and Alessandra Fogli. 2009. “Culture: An Empirical Investigation of Beliefs, Work, and Fertility." American Economic Journal: Macroeconomics 1 (January): 146-177.

Fryer, Roland G. and Steven D. Levitt. 2010. "An Empirical Analysis of the Gender Gap in Mathematics.” American Economic Journal: Applied Economics 2 (April): 210-240.

Gauthier, Anne H., Timothy M. Smeeding, and Frank F. Furstenberg. 2004. "Are Parents Investing Less Time in Children? Trends in Selected Industrialized Countries." Population and Development Review (December): 647-671. 
Goldin, Claudia. 2014. “A Grand Gender Convergence: Its Last Chapter.” American Economic Review 104 (April): 1091-1119.

Guiso, Luigi, Ferdinando Monte, Paola Sapienza, and Luigi Zingales. 2008. "Education Forum: Culture, Gender, and Math.” Science 320: 1164-1165.

Guryan, Jonathan, Erik Hurst, and Melissa Kearney. 2008. "Parental Education and Parental Time with Children." Journal of Economic Perspectives 22 (Summer): 23-26.

Harms, Tersa, Jonathan Gershuny, Aiden Doherty, Emma Thomas, Karen Milton, and Charlie Foster. 2019. "A Validation Study of the Eurostat Harmonised European Time Use Study (HETUS) Diary Using Wearable Technology.” BMP Public Health 19 (Supplement 2): 455-464.

Hausmann, Ricardo, Laura D. Tyson, and Saadia Zahidi. 2007. The Global Gender Gap Report 2007. Geneva, Switzerland: World Economic Forum.

Hersch, Joni. 2009. "Home Production and Wages: Evidence from the American Time Use Survey." Review of Economics of the Household 7 (June): 159-178.

Hochschild, Arlie R. 1989. The Second Shift. New York: Avon Books.

Kan, Man Yee and Stephen Pudney. 2008. "Measurement Error in Stylized and Diary Data on Time Use." Sociological Methodology 38(1): 101-132.

Kleven, Henrik, Camille Landais, and Jakob Egholt Søgaard. 2019. "Children and Gender Inequality: Evidence from Denmark." American Economic Journal: Applied Economics 11 (October): 181-209.

Kosteas, Vasilios D. 2013. "Gender Role Attitudes, Labor Supply, and Human Capital Formation.” Industrial Relations 52 (October): 915-940.

Le Barbanchon, Thomas, Roland Rathelot, and Alexandra Roulet. 2019. "Gender Differences in Job Search: Trading off Commute Against Wage." Available at SSRN: https://ssrn.com/abstract=3467750.

Lubotsky, Darren. 2007. "Chutes or Ladders? A Longitudinal Analysis of Immigrant Earnings." Journal of Political Economy 115 (October): 820-867.

Lundberg, Shelly. 2005. "Sons, Daughters, and Parental Behavior." Oxford Review of Economic Policy 21, No. 3 (Autumn): 340-356.

Mincer, Jacob. 1962. "Labor Force Participation of Married Women," in H. Gregg Lewis ed., Aspects of Labor Economics, Universities National Bureau of Economic Research Conference Series 14 (Princeton, NJ: Princeton University Press), pp. 63-97.

Mincer, Jacob, and Solomon Polachek. 1974. "Family Investment in Human Capital: Earnings of Women." Journal of Political Economy 82(Mar.-Apr.): S76-S108. 
Murray-Close, Marta and Misty L. Heggeness. 2018. "Manning Up and Womaning Down: How Husbands and Wives Report Their Earnings When She Earns More.” SESHD Working Paper \#2018-20. United States Census Bureau.

Nollenberger, Natalia, Núria Rodríguez-Planas, and Almudena Sevilla. 2016. "The Math Gender Gap: The Role of Culture." American Economic Review 106 (May): 257-261.

Ralsmark, Hilda. 2017. "Education, Norms, and Gender Equality." Working Paper in Economics No. 702, Department of Economics, University of Gothenburg.

Waldfogel, Jane. 1998. "Understanding the 'Family Gap' in Pay for Women with Children." Journal of Economic Perspectives 12 (Winter): 137-56.

Zentner, M. and K. Mitura, "Stepping Out of the Caveman's Shadow: Nations' Gender Gap Predicts Degree of Sex Differentiation in Mate Preferences." 2012. Psychological Science 25: 1176-1185.

Zinovyeva, Natalia and Maryna Tverdostup. 2018. "Gender Identity, Co-Working Spouses and Relative Income within Households.” IZA Discussion Paper No. 11757. 


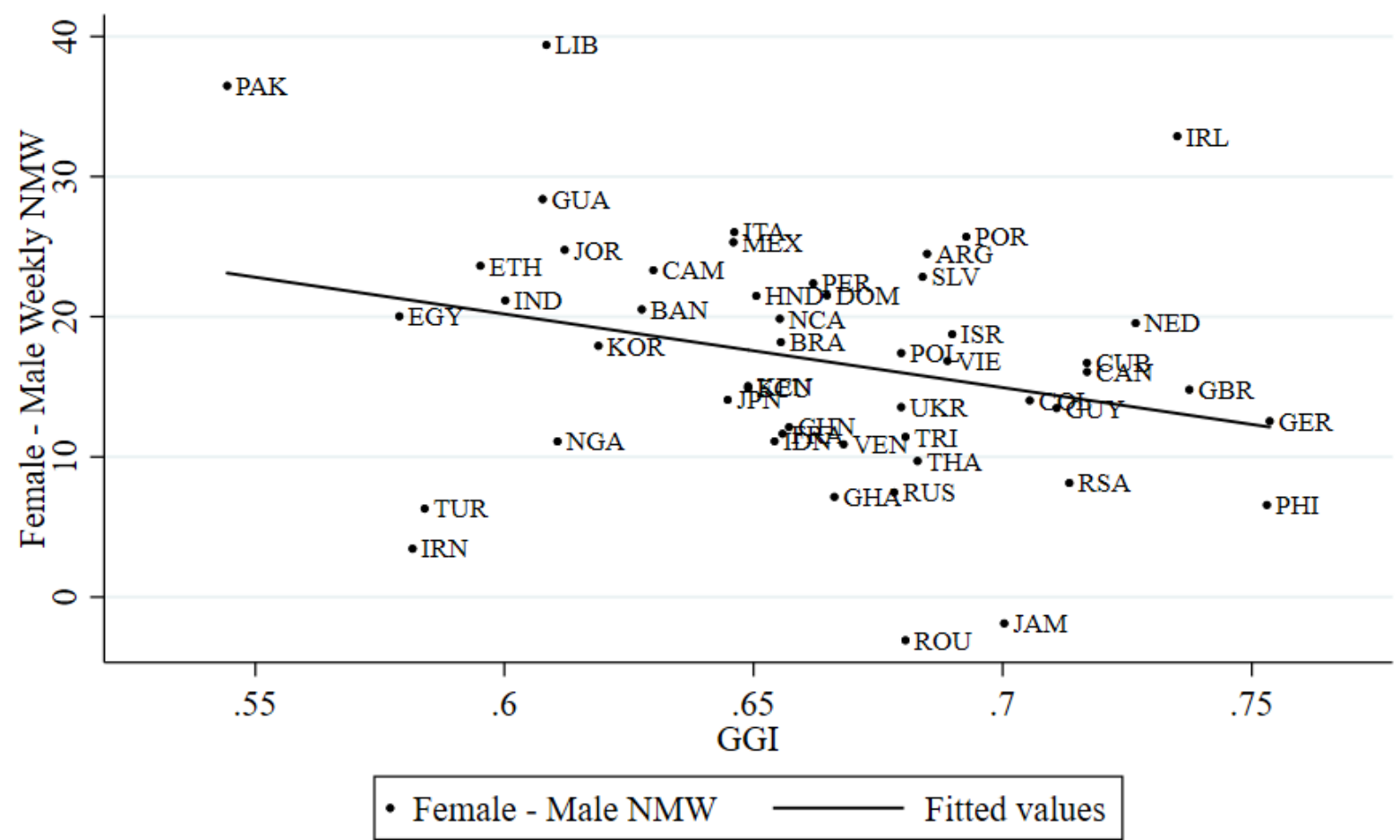

Fitted Line: $\beta=-52.54$, s.e. $=25.02$. Female - Male NMW is computed as mean female non-market work per week minus mean male non-market work per week, by country. The regression line weights all countries equally. Countries with fewer than 30 ATUS observations were dropped.

Figure 1: GGI and Female-Male Non-Market Work (NMW) Differential by Country 
Table 1: Total Non-Market Work, Housework, and Childcare by Gender and Immigrant Generation

\begin{tabular}{|c|c|c|c|c|}
\hline \multicolumn{5}{|c|}{ I. All Men and Women } \\
\hline \multicolumn{5}{|c|}{ Panel A. Women } \\
\hline & All & $\begin{array}{c}\text { Natives with Native } \\
\text { Parents }\end{array}$ & Immigrants & $\begin{array}{c}\text { Second-Generation } \\
\text { Immigrants }\end{array}$ \\
\hline Non-Market Work & 27.63 & 26.26 & 33.09 & 28.48 \\
\hline Housework & 18.11 & 17.11 & 22.45 & 17.51 \\
\hline Childcare & 6.98 & 6.476 & 8.584 & 8.534 \\
\hline $\mathrm{N}$ & 38,582 & 29,639 & 6,618 & 2,325 \\
\hline \multicolumn{5}{|c|}{ Panel B. Men } \\
\hline & All & $\begin{array}{c}\text { Natives with Native } \\
\text { Parents }\end{array}$ & Immigrants & $\begin{array}{c}\text { Second-Generation } \\
\text { Immigrants } \\
\end{array}$ \\
\hline Non-Market Work & 15.14 & 15.51 & 13.29 & 15.94 \\
\hline Housework & 10.14 & 10.67 & 7.822 & 10.30 \\
\hline Childcare & 3.491 & 3.345 & 3.919 & 4.120 \\
\hline $\mathrm{N}$ & 34,866 & 27,033 & 5,837 & 1,996 \\
\hline \multicolumn{5}{|c|}{ Panel C. Women-Men } \\
\hline & All & $\begin{array}{c}\text { Natives with Native } \\
\text { Parents }\end{array}$ & Immigrants & $\begin{array}{c}\text { Second-Generation } \\
\text { Immigrants } \\
\end{array}$ \\
\hline Non-Market Work & 12.49 & 10.75 & 19.8 & 12.54 \\
\hline Housework & 7.97 & 6.44 & 14.628 & 7.21 \\
\hline Childcare & 3.489 & 3.131 & 4.665 & 4.414 \\
\hline \multicolumn{5}{|c|}{ II. Men and Women with Children Under Age 18} \\
\hline \multicolumn{5}{|c|}{ Panel A. Women } \\
\hline & All & $\begin{array}{c}\text { Natives with Native } \\
\text { Parents } \\
\end{array}$ & Immigrants & $\begin{array}{l}\text { Second-Generation } \\
\text { Immigrants }\end{array}$ \\
\hline Non-Market Work & 33.43 & 31.95 & 38.04 & 33.15 \\
\hline Housework & 18.83 & 17.35 & 23.73 & 17.61 \\
\hline Childcare & 12.68 & 12.66 & 12.42 & 13.70 \\
\hline $\mathrm{N}$ & 26,161 & 19,480 & 4,994 & 1,687 \\
\hline \multicolumn{5}{|c|}{ Panel B. Men } \\
\hline & All & $\begin{array}{c}\text { Natives with Native } \\
\text { Parents }\end{array}$ & Immigrants & $\begin{array}{c}\text { Second-Generation } \\
\text { Immigrants } \\
\end{array}$ \\
\hline Non-Market Work & 16.89 & 17.58 & 14.54 & 17.64 \\
\hline Housework & 9.317 & 9.888 & 7.493 & 9.462 \\
\hline Childcare & 6.386 & 6.568 & 5.652 & 6.997 \\
\hline $\mathrm{N}$ & 23,276 & 17,509 & 4,382 & 1,380 \\
\hline \multicolumn{5}{|c|}{ Panel C. Women-Men } \\
\hline & All & $\begin{array}{c}\text { Natives with Native } \\
\text { Parents }\end{array}$ & Immigrants & $\begin{array}{l}\text { Second-Generation } \\
\text { Immigrants }\end{array}$ \\
\hline Non-Market Work & 16.54 & 14.37 & 23.5 & 15.51 \\
\hline Housework & 9.513 & 7.462 & 16.237 & 8.148 \\
\hline Childcare & 6.294 & 6.092 & 6.768 & 6.703 \\
\hline
\end{tabular}

Notes: Data are from waves 2003-2017 of the ATUS. Variables are measured in hours per week. The sample includes respondents aged 18-64 who are married with a spouse aged 18-64 present in the household. Observations that fall on public holidays, natives born abroad, and same sex couples are excluded. Data are weighted using ATUS sampling weights adjusted so that each year receives the same weight. 
Table 2: Regression-Adjusted Relationship Between Non-Market Work and Immigrant Generation

\begin{tabular}{|c|c|c|c|c|c|c|c|c|c|}
\hline & $\begin{array}{c}(1) \\
\text { Total Non- } \\
\text { Market Work }\end{array}$ & $\begin{array}{c}(2) \\
\text { Total Non- } \\
\text { Market Work }\end{array}$ & $\begin{array}{c}\text { (3) } \\
\text { Total Non- } \\
\text { Market Work }\end{array}$ & $\begin{array}{c}\text { (4) } \\
\text { Housework }\end{array}$ & $\begin{array}{c}\text { (5) } \\
\text { Housework }\end{array}$ & $\begin{array}{c}(6) \\
\text { Housework }\end{array}$ & $\begin{array}{c}\text { (7) } \\
\text { Childcare }\end{array}$ & $\begin{array}{c}(8) \\
\text { Childcare }\end{array}$ & $\begin{array}{c}\text { (9) } \\
\text { Childcare }\end{array}$ \\
\hline \multicolumn{10}{|l|}{ Panel A: All Women } \\
\hline Immigrant & $\begin{array}{c}5.698^{* * *} \\
(0.438)\end{array}$ & $\begin{array}{c}3.809^{* * * *} \\
(0.425)\end{array}$ & $\begin{array}{c}2.690 * * * \\
(0.404)\end{array}$ & $\begin{array}{c}5.297^{* * *} \\
(0.332)\end{array}$ & $\begin{array}{c}3.913^{* * * *} \\
(0.338)\end{array}$ & $\begin{array}{c}3.197 * * * \\
(0.328)\end{array}$ & $\begin{array}{c}0.766^{* * *} \\
(0.227)\end{array}$ & $\begin{array}{c}0.269 \\
(0.199)\end{array}$ & $\begin{array}{l}-0.0101 \\
(0.196)\end{array}$ \\
\hline Second-Generation Immigrant & $\begin{array}{l}0.840^{*} \\
(0.509) \\
\end{array}$ & $\begin{array}{c}0.565 \\
(0.479) \\
\end{array}$ & $\begin{array}{c}0.613 \\
(0.456) \\
\end{array}$ & $\begin{array}{c}0.178 \\
(0.385) \\
\end{array}$ & $\begin{array}{c}0.423 \\
(0.381) \\
\end{array}$ & $\begin{array}{c}0.454 \\
(0.370) \\
\end{array}$ & $\begin{array}{c}0.683^{* * *} \\
(0.263) \\
\end{array}$ & $\begin{array}{l}0.0869 \\
(0.224) \\
\end{array}$ & $\begin{array}{c}0.101 \\
(0.221) \\
\end{array}$ \\
\hline Observations & 38,582 & 38,565 & 38,565 & 38,582 & 38,565 & 38,565 & 38,582 & 38,565 & 38,565 \\
\hline R-squared & 0.045 & 0.159 & 0.239 & 0.047 & 0.072 & 0.128 & 0.162 & 0.397 & 0.414 \\
\hline Mean & 27.63 & 27.64 & 27.64 & 18.11 & 18.11 & 18.11 & 6.980 & 6.980 & 6.980 \\
\hline \multicolumn{10}{|c|}{ Panel B: Women With at Least One Child Under 18} \\
\hline Immigrant & $\begin{array}{c}6.760^{* * *} \\
(0.516)\end{array}$ & $\begin{array}{c}5.073 * * * \\
(0.516)\end{array}$ & $\begin{array}{c}3.189^{* * * *} \\
(0.486)\end{array}$ & $\begin{array}{c}6.058^{* * * *} \\
(0.372)\end{array}$ & $\begin{array}{c}4.534^{* * * *} \\
(0.382)\end{array}$ & $\begin{array}{c}3.466^{* * *} \\
(0.369)\end{array}$ & $\begin{array}{l}0.753^{* *} \\
(0.310)\end{array}$ & $\begin{array}{l}0.666^{* *} \\
(0.300)\end{array}$ & $\begin{array}{l}-0.0334 \\
(0.293)\end{array}$ \\
\hline Second-Generation Immigrant & $\begin{array}{c}0.769 \\
(0.609) \\
\end{array}$ & $\begin{array}{c}0.412 \\
(0.587) \\
\end{array}$ & $\begin{array}{c}0.776 \\
(0.551) \\
\end{array}$ & $\begin{array}{r}-0.0469 \\
(0.439) \\
\end{array}$ & $\begin{array}{c}0.254 \\
(0.434) \\
\end{array}$ & $\begin{array}{c}0.455 \\
(0.419) \\
\end{array}$ & $\begin{array}{l}0.909 * * \\
(0.366) \\
\end{array}$ & $\begin{array}{c}0.218 \\
(0.341) \\
\end{array}$ & $\begin{array}{c}0.361 \\
(0.332) \\
\end{array}$ \\
\hline Observations & 26,161 & 26,150 & 26,150 & 26,161 & 26,150 & 26,150 & 26,161 & 26,150 & 26,150 \\
\hline R-squared & 0.047 & 0.120 & 0.224 & 0.056 & 0.084 & 0.147 & 0.123 & 0.246 & 0.283 \\
\hline Mean & 33.43 & 33.44 & 33.44 & 18.83 & 18.83 & 18.83 & 12.68 & 12.68 & 12.68 \\
\hline \multicolumn{10}{|l|}{ Panel C: All Men } \\
\hline Immigrant & $\begin{array}{c}-2.126^{* * *} \\
(0.363)\end{array}$ & $\begin{array}{c}-2.127^{* * *} \\
(0.368)\end{array}$ & $\begin{array}{c}-1.930^{* * *} \\
(0.368)\end{array}$ & $\begin{array}{c}-2.084^{* * *} \\
(0.297)\end{array}$ & $\begin{array}{c}-1.812 * * * \\
(0.306)\end{array}$ & $\begin{array}{c}-1.648^{* * *} \\
(0.306)\end{array}$ & $\begin{array}{l}0.0589 \\
(0.168)\end{array}$ & $\begin{array}{l}-0.220 \\
(0.161)\end{array}$ & $\begin{array}{l}-0.183 \\
(0.161)\end{array}$ \\
\hline Second-Generation Immigrant & $\begin{array}{r}0.0354 \\
(0.438) \\
\end{array}$ & $\begin{array}{l}-0.228 \\
(0.433) \\
\end{array}$ & $\begin{array}{l}-0.184 \\
(0.432) \\
\end{array}$ & $\begin{array}{r}-0.309 \\
(0.359) \\
\end{array}$ & $\begin{array}{r}-0.254 \\
(0.359) \\
\end{array}$ & $\begin{array}{r}-0.218 \\
(0.359) \\
\end{array}$ & $\begin{array}{l}0.437^{* *} \\
(0.203) \\
\end{array}$ & $\begin{array}{l}0.0603 \\
(0.189) \\
\end{array}$ & $\begin{array}{r}0.0686 \\
(0.189) \\
\end{array}$ \\
\hline Observations & 34,866 & 34,858 & 34,858 & 34,866 & 34,858 & 34,858 & 34,866 & 34,858 & 34,858 \\
\hline R-squared & 0.055 & 0.081 & 0.084 & 0.064 & 0.065 & 0.068 & 0.083 & 0.212 & 0.212 \\
\hline Mean & 15.14 & 15.14 & 15.14 & 10.14 & 10.14 & 10.14 & 3.491 & 3.491 & 3.491 \\
\hline \multicolumn{10}{|c|}{ Panel D: Men With at Least One Child Under 18} \\
\hline Immigrant & $\begin{array}{c}-1.907^{* * *} \\
(0.434)\end{array}$ & $\begin{array}{c}-1.819^{* * *} \\
(0.446)\end{array}$ & $\begin{array}{c}-1.490^{* * *} \\
(0.445)\end{array}$ & $\begin{array}{c}-1.871 * * * \\
(0.326)\end{array}$ & $\begin{array}{c}-1.705^{* * *} \\
(0.338)\end{array}$ & $\begin{array}{c}-1.487 * * * \\
(0.338)\end{array}$ & $\begin{array}{c}-0.0863 \\
(0.250)\end{array}$ & $\begin{array}{l}-0.124 \\
(0.250)\end{array}$ & $\begin{array}{c}-0.0142 \\
(0.250)\end{array}$ \\
\hline Second-Generation Immigrant & $\begin{array}{c}0.362 \\
(0.538) \\
\end{array}$ & $\begin{array}{l}0.0595 \\
(0.533) \\
\end{array}$ & $\begin{array}{c}0.102 \\
(0.532) \\
\end{array}$ & $\begin{array}{c}-0.148 \\
(0.404) \\
\end{array}$ & $\begin{array}{r}-0.0816 \\
(0.405) \\
\end{array}$ & $\begin{array}{r}-0.0552 \\
(0.404) \\
\end{array}$ & $\begin{array}{l}0.602^{*} \\
(0.310)\end{array}$ & $\begin{array}{c}0.180 \\
(0.299) \\
\end{array}$ & $\begin{array}{c}0.195 \\
(0.299) \\
\end{array}$ \\
\hline Observations & 23,276 & 23,271 & 23,271 & 23,276 & 23,271 & 23,271 & 23,276 & 23,271 & 23,271 \\
\hline R-squared & 0.070 & 0.089 & 0.095 & 0.072 & 0.074 & 0.079 & 0.054 & 0.123 & 0.125 \\
\hline Mean & 16.89 & 16.89 & 16.89 & 9.317 & 9.316 & 9.316 & 6.386 & 6.387 & 6.387 \\
\hline $\begin{array}{l}\text { Education, Children, and Spouse Controls } \\
\text { Wife's Market Work Controls }\end{array}$ & & $\mathrm{X}$ & $\begin{array}{l}\mathrm{X} \\
\mathrm{X} \\
\end{array}$ & & $\mathrm{X}$ & $\begin{array}{l}\mathrm{X} \\
\mathrm{X} \\
\end{array}$ & & $\mathrm{X}$ & $\begin{array}{l}\mathrm{X} \\
\mathrm{X} \\
\end{array}$ \\
\hline $\begin{array}{l}\text { Notes: Data are from waves } 2003-2017 \text { of the ATU } \\
\text { the household. Observations that fall on public hol } \\
\text { set of race/ethnicity dummy variables, as well as fi } \\
\text { continuous variables for the number of children in } \\
\text { of hours worked by the wife in the relationship, as } \\
\text { parentheses }\left(* * \mathrm{p}<0.01,{ }^{* *} \mathrm{p}<0.05,{ }^{*} \mathrm{p}<0.1\right)\end{array}$ & $\begin{array}{l}\text { effects for state, sur } \\
\text { age ranges } 0-5,6-12 \\
1 \text { as a dummy varial }\end{array}$ & dicating if the & Ine depende & are weighte & 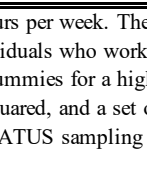 & adjusted sc & year recei & $\begin{array}{l}\text { with a spou } \\
\text { respondents } \\
\text { or more. Ch }\end{array}$ & $\begin{array}{l}8-64 \text { present in } \\
\text { esquared, and a } \\
\text { ntrols are } \\
\text { e weekly numbe } \\
\text { ors are in }\end{array}$ \\
\hline
\end{tabular}


Table 3: Effect of Source Country Characteristics on Non-Market Work for Female Immigrants

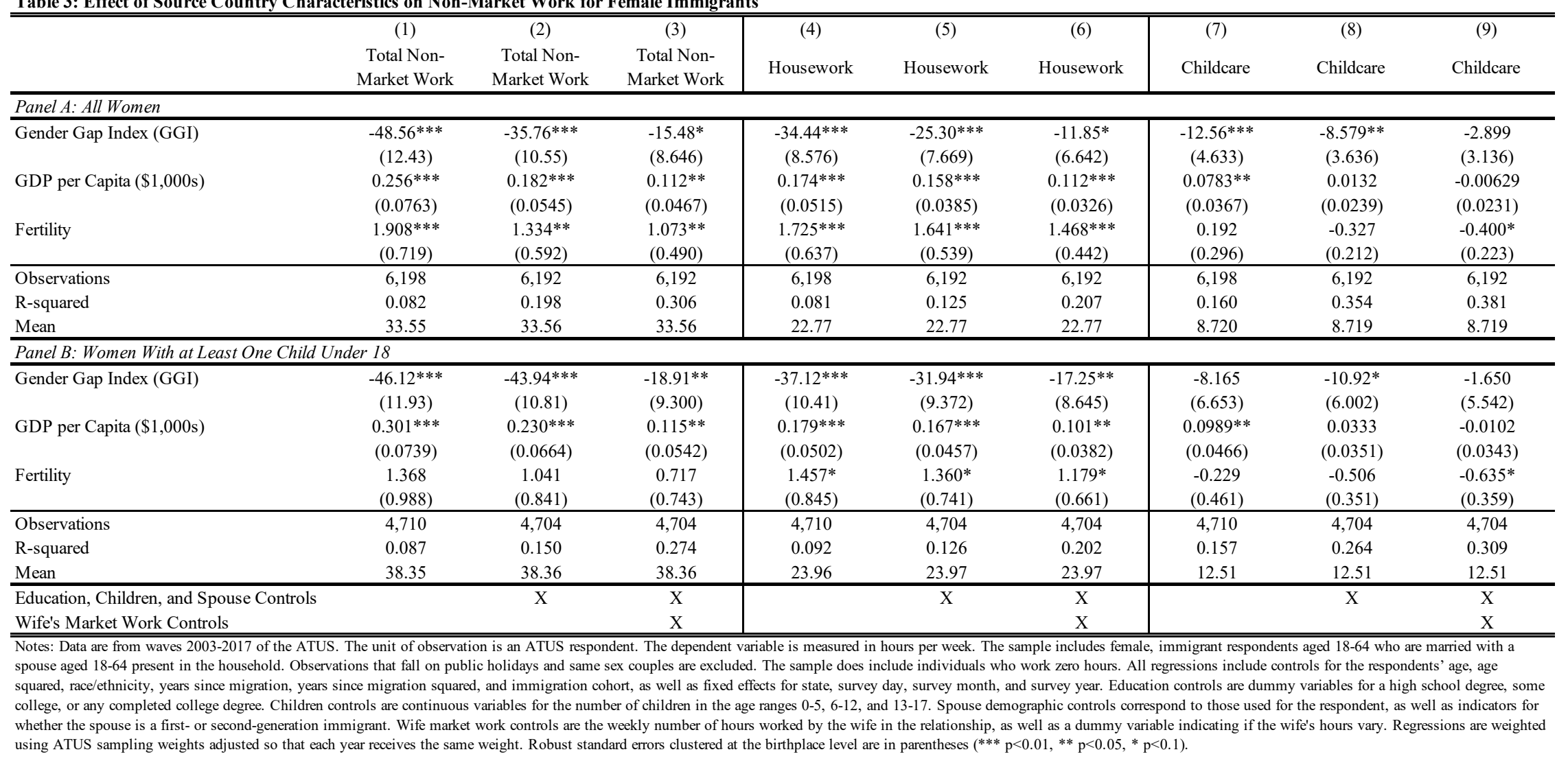


Table 4: Effect of Source Country Characteristics on Non-Market Work for Male Immigrants

\begin{tabular}{|c|c|c|c|c|c|c|c|c|c|}
\hline & $\begin{array}{c}(1) \\
\text { Total Non- } \\
\text { Market Work }\end{array}$ & $\begin{array}{c}(2) \\
\text { Total Non- } \\
\text { Market Work }\end{array}$ & $\begin{array}{c}(3) \\
\text { Total Non- } \\
\text { Market Work }\end{array}$ & $\begin{array}{c}\text { (4) } \\
\text { Housework }\end{array}$ & $\begin{array}{c}\text { (5) } \\
\text { Housework }\end{array}$ & $\begin{array}{c}(6) \\
\text { Housework }\end{array}$ & $\begin{array}{c}\text { (7) } \\
\text { Childcare }\end{array}$ & $\begin{array}{c}\text { (8) } \\
\text { Childcare }\end{array}$ & $\begin{array}{c}\text { (9) } \\
\text { Childcare }\end{array}$ \\
\hline \multicolumn{10}{|l|}{ Panel A: All Men } \\
\hline Gender Gap Index (GGI) & $\begin{array}{c}27.07 * * * \\
(7.987)\end{array}$ & $\begin{array}{c}26.10^{* * *} \\
(8.492)\end{array}$ & $\begin{array}{c}22.43^{* * * *} \\
(8.163)\end{array}$ & $\begin{array}{c}21.26^{* * *} \\
(6.963)\end{array}$ & $\begin{array}{c}18.25^{* * * *} \\
(6.599)\end{array}$ & $\begin{array}{l}15.08^{* *} \\
(6.297)\end{array}$ & $\begin{array}{c}4.334 \\
(3.012)\end{array}$ & $\begin{array}{l}6.385^{* *} \\
(2.861)\end{array}$ & $\begin{array}{l}5.529^{*} \\
(2.924)\end{array}$ \\
\hline GDP per Capita $(\$ 1,000 \mathrm{~s})$ & $\begin{array}{c}0.0132 \\
(0.0470)\end{array}$ & $\begin{array}{l}-0.0228 \\
(0.0492)\end{array}$ & $\begin{array}{l}-0.0160 \\
(0.0491)\end{array}$ & $\begin{array}{l}-0.0253 \\
(0.0375)\end{array}$ & $\begin{array}{l}-0.0423 \\
(0.0384)\end{array}$ & $\begin{array}{l}-0.0367 \\
(0.0379)\end{array}$ & $\begin{array}{l}0.0505^{*} \\
(0.0297)\end{array}$ & $\begin{array}{c}0.0276 \\
(0.0265)\end{array}$ & $\begin{array}{c}0.0290 \\
(0.0265)\end{array}$ \\
\hline Fertility & $\begin{array}{c}0.549 \\
(0.445) \\
\end{array}$ & $\begin{array}{c}0.241 \\
(0.460) \\
\end{array}$ & $\begin{array}{c}0.143 \\
(0.445) \\
\end{array}$ & $\begin{array}{c}0.202 \\
(0.389) \\
\end{array}$ & $\begin{array}{c}0.110 \\
(0.401) \\
\end{array}$ & $\begin{array}{r}0.0195 \\
(0.386) \\
\end{array}$ & $\begin{array}{l}0.377^{*} \\
(0.208)\end{array}$ & $\begin{array}{c}0.126 \\
(0.189) \\
\end{array}$ & $\begin{array}{c}0.100 \\
(0.192) \\
\end{array}$ \\
\hline Observations & 5,461 & 5,458 & 5,458 & 5,461 & 5,458 & 5,458 & 5,461 & 5,458 & 5,458 \\
\hline R-squared & 0.071 & 0.094 & 0.102 & 0.075 & 0.082 & 0.091 & 0.072 & 0.157 & 0.159 \\
\hline Mean & 13.30 & 13.30 & 13.30 & 7.848 & 7.847 & 7.847 & 3.943 & 3.945 & 3.945 \\
\hline \multicolumn{10}{|c|}{ Panel B: Men With at Least One Child Under 18} \\
\hline Gender Gap Index (GGI) & $\begin{array}{c}32.87 * * * \\
(7.497)\end{array}$ & $\begin{array}{c}31.49 * * * \\
(8.544)\end{array}$ & $\begin{array}{c}26.79 * * * \\
(8.557)\end{array}$ & $\begin{array}{c}21.07^{* * *} \\
(7.141)\end{array}$ & $\begin{array}{l}19.58^{* *} \\
(7.513)\end{array}$ & $\begin{array}{l}16.16^{* *} \\
(7.469)\end{array}$ & $\begin{array}{c}12.57^{* * *} \\
(3.934)\end{array}$ & $\begin{array}{c}11.96^{* * *} \\
(3.744)\end{array}$ & $\begin{array}{c}10.67 * * * \\
(3.931)\end{array}$ \\
\hline GDP per Capita $(\$ 1,000 \mathrm{~s})$ & $\begin{array}{c}0.0286 \\
(0.0619)\end{array}$ & $\begin{array}{l}-0.00172 \\
(0.0661)\end{array}$ & $\begin{array}{l}0.00948 \\
(0.0664)\end{array}$ & $\begin{array}{l}-0.0147 \\
(0.0389)\end{array}$ & $\begin{array}{l}-0.0308 \\
(0.0413)\end{array}$ & $\begin{array}{l}-0.0224 \\
(0.0426)\end{array}$ & $\begin{array}{c}0.0629 \\
(0.0396)\end{array}$ & $\begin{array}{c}0.0462 \\
(0.0355)\end{array}$ & $\begin{array}{c}0.0494 \\
(0.0352)\end{array}$ \\
\hline Fertility & $\begin{array}{r}-0.0433 \\
(0.468) \\
\end{array}$ & $\begin{array}{l}-0.200 \\
(0.503) \\
\end{array}$ & $\begin{array}{l}-0.311 \\
(0.488) \\
\end{array}$ & $\begin{array}{l}-0.233 \\
(0.376) \\
\end{array}$ & $\begin{array}{l}-0.293 \\
(0.415) \\
\end{array}$ & $\begin{array}{l}-0.384 \\
(0.404) \\
\end{array}$ & $\begin{array}{c}0.384 \\
(0.286) \\
\end{array}$ & $\begin{array}{c}0.260 \\
(0.257) \\
\end{array}$ & $\begin{array}{c}0.223 \\
(0.262) \\
\end{array}$ \\
\hline Observations & 4,127 & 4,125 & 4,125 & 4,127 & 4,125 & 4,125 & 4,127 & 4,125 & 4,125 \\
\hline R-squared & 0.083 & 0.098 & 0.107 & 0.083 & 0.089 & 0.098 & 0.080 & 0.127 & 0.129 \\
\hline Mean & 14.50 & 14.50 & 14.50 & 7.513 & 7.509 & 7.509 & 5.629 & 5.634 & 5.634 \\
\hline Education, Children, and Spouse Controls & & $\mathrm{X}$ & $\mathrm{X}$ & & $\mathrm{X}$ & $\mathrm{X}$ & & $\mathrm{X}$ & $\mathrm{X}$ \\
\hline Wife's Market Work Controls & & & $\mathrm{X}$ & & & $\mathrm{X}$ & & & $\mathrm{X}$ \\
\hline
\end{tabular}


Table 5: Effect of an Increase in GGI from India's to Canada's Value on the Gender Gap in Non-Market Work for Immigrants

\begin{tabular}{|c|c|c|c|c|c|c|c|c|c|}
\hline \multicolumn{10}{|c|}{ I. Mean Values } \\
\hline \multicolumn{5}{|c|}{ Panel A. All Immigrants } & \multicolumn{5}{|c|}{ Panel B. Immigrants with at Least One Child Under 18} \\
\hline & Women & Men & W-M & & & Women & Men & $\mathrm{W}-\mathrm{M}$ & \\
\hline Total & 33.56 & 13.30 & 20.25 & & Total & 38.36 & 14.50 & 23.86 & \\
\hline Housework & 22.77 & 7.85 & 14.93 & & Housework & 23.97 & 7.51 & 16.46 & \\
\hline Childcare & 8.72 & 3.95 & 4.77 & & Childcare & 12.51 & 5.63 & 6.88 & \\
\hline \multicolumn{10}{|c|}{ II. Effect of a 0.12 change in GGI (India to Canada) } \\
\hline \multicolumn{5}{|c|}{ Panel A. All Immigrants } & \multicolumn{5}{|c|}{ Panel B. Immigrants with at Least One Child Under 18} \\
\hline & Women & Men & W-M & $\begin{array}{c}(\mathrm{W}-\mathrm{M}) / \\
\text { Mean Gap }\end{array}$ & & Women & Men & W-M & $\begin{array}{c}(\mathrm{W}-\mathrm{M}) / \\
\text { Mean Gap }\end{array}$ \\
\hline Total & $\begin{array}{c}-4.292 * * * \\
(1.266)\end{array}$ & $\begin{array}{c}3.132 * * * \\
(1.019)\end{array}$ & $\begin{array}{c}-7.424 * * * \\
(1.625)\end{array}$ & $\begin{array}{c}-0.367 * * * \\
(0.080)\end{array}$ & Total & $\begin{array}{c}-5.273 * * * \\
(1.297)\end{array}$ & $\begin{array}{c}3.779 * * * \\
(1.025)\end{array}$ & $\begin{array}{c}-9.052 * * * \\
(1.654)\end{array}$ & $\begin{array}{c}-0.379 * * * \\
(0.069)\end{array}$ \\
\hline Housework & $\begin{array}{c}-3.036^{* * *} \\
(0.920)\end{array}$ & $\begin{array}{c}2.190 * * * \\
(0.792)\end{array}$ & $\begin{array}{c}-5.226 * * * \\
(1.214)\end{array}$ & $\begin{array}{c}-0.350 * * * \\
(0.081)\end{array}$ & Housework & $\begin{array}{c}-3.833^{* * *} \\
(1.125)\end{array}$ & $\begin{array}{c}2.349 * * \\
(0.902)\end{array}$ & $\begin{array}{c}-6.182 * * * \\
(1.441)\end{array}$ & $\begin{array}{c}-0.375^{* * *} \\
(0.088)\end{array}$ \\
\hline Childcare & $\begin{array}{c}-1.029 * * \\
(0.436)\end{array}$ & $\begin{array}{c}0.766 * * \\
(0.343)\end{array}$ & $\begin{array}{c}-1.796 * * * \\
(0.555)\end{array}$ & $\begin{array}{c}-0.376^{* * *} \\
(0.116)\end{array}$ & Childcare & $\begin{array}{c}-1.310^{*} \\
(0.720)\end{array}$ & $\begin{array}{c}1.435 * * * \\
(0.449)\end{array}$ & $\begin{array}{c}-2.745^{* * *} \\
(0.849)\end{array}$ & $\begin{array}{c}-0.399 * * * \\
(0.123)\end{array}$ \\
\hline
\end{tabular}

standard errors are in parentheses $(* * * \mathrm{p}<0.01, * * \mathrm{p}<0.05, * \mathrm{p}<0.1)$. 
Table 6: Combined Effect of Own and Partner GGI on Non-Market Work for Immigrants with Immigrant Partners

\begin{tabular}{|c|c|c|c|c|c|c|}
\hline & $\begin{array}{c}(1) \\
\text { Total Non-Market } \\
\text { Work }\end{array}$ & $\begin{array}{l}\text { (2) } \\
\text { Housework }\end{array}$ & $\begin{array}{c}\text { (3) } \\
\text { Childcare }\end{array}$ & $\begin{array}{c}\text { (4) } \\
\text { Total Non-Market } \\
\text { Work }\end{array}$ & $\begin{array}{c}\text { (5) } \\
\text { Housework }\end{array}$ & $\begin{array}{c}\text { (6) } \\
\text { Childcare }\end{array}$ \\
\hline & \multicolumn{3}{|c|}{ Panel A. All Women } & \multicolumn{3}{|c|}{ Panel B. All Men } \\
\hline Own GGI & $\begin{array}{c}-51.38 * * * \\
(18.39)\end{array}$ & $\begin{array}{c}-37.14 * * \\
(17.83)\end{array}$ & $\begin{array}{l}-5.164 \\
(10.13)\end{array}$ & $\begin{array}{c}16.76 \\
(22.09)\end{array}$ & $\begin{array}{c}7.875 \\
(9.873)\end{array}$ & $\begin{array}{c}9.583 \\
(13.83)\end{array}$ \\
\hline Partner GGI & $\begin{array}{c}9.780 \\
(18.34) \\
\end{array}$ & $\begin{array}{c}9.315 \\
(14.49) \\
\end{array}$ & $\begin{array}{l}-6.466 \\
(11.58) \\
\end{array}$ & $\begin{array}{c}6.324 \\
(20.97) \\
\end{array}$ & $\begin{array}{r}7.388 \\
(9.209) \\
\end{array}$ & $\begin{array}{l}-4.347 \\
(14.94) \\
\end{array}$ \\
\hline Sum of Own and Partner GGI & $\begin{array}{c}-41.598 * * * \\
(12.127) \\
\end{array}$ & $\begin{array}{c}-27.821 * * * \\
(8.199)\end{array}$ & $\begin{array}{c}-11.630 * * \\
(5.110) \\
\end{array}$ & $\begin{array}{c}23.087 * * \\
(10.157) \\
\end{array}$ & $\begin{array}{c}15.263^{* *} \\
(7.246) \\
\end{array}$ & $\begin{array}{c}5.235 \\
(3.398) \\
\end{array}$ \\
\hline $\begin{array}{l}\text { Observations } \\
\text { R-squared } \\
\text { Mean }\end{array}$ & $\begin{array}{l}4,738 \\
0.199 \\
34.63\end{array}$ & $\begin{array}{l}4,738 \\
0.128 \\
23.74 \\
\end{array}$ & $\begin{array}{l}4,738 \\
0.347 \\
8.792 \\
\end{array}$ & $\begin{array}{l}4,305 \\
0.101 \\
13.06\end{array}$ & $\begin{array}{l}4,305 \\
0.085 \\
7.550\end{array}$ & $\begin{array}{l}4,305 \\
0.173 \\
3.866 \\
\end{array}$ \\
\hline Mean & \multicolumn{3}{|c|}{ Panel C. Women With at Least One Child Under 18} & \multicolumn{3}{|c|}{ Panel D. Men With at Least One Child Under 18} \\
\hline Own GGI & $\begin{array}{c}-65.73 * * \\
(25.79)\end{array}$ & $\begin{array}{l}-47.56 \\
(29.08)\end{array}$ & $\begin{array}{l}-14.12 \\
(14.99)\end{array}$ & $\begin{array}{c}50.14 \\
(34.19)\end{array}$ & $\begin{array}{c}26.52 \\
(17.88)\end{array}$ & $\begin{array}{c}15.34 \\
(23.94)\end{array}$ \\
\hline Partner GGI & $\begin{array}{c}17.72 \\
(26.69) \\
\end{array}$ & $\begin{array}{c}13.38 \\
(25.04) \\
\end{array}$ & $\begin{array}{c}1.752 \\
(16.31) \\
\end{array}$ & $\begin{array}{l}-14.95 \\
(33.48) \\
\end{array}$ & $\begin{array}{l}-2.824 \\
(16.31) \\
\end{array}$ & $\begin{array}{l}-3.941 \\
(24.75) \\
\end{array}$ \\
\hline Sum of Own and Partner GGI & $\begin{array}{c}-48.007 * * * \\
(12.939) \\
\end{array}$ & $\begin{array}{c}-34.181 * * * \\
(9.241) \\
\end{array}$ & $\begin{array}{l}-12.366 \\
(8.164) \\
\end{array}$ & $\begin{array}{c}35.188 * * * \\
(9.523) \\
\end{array}$ & $\begin{array}{c}23.698 * * * \\
(8.436) \\
\end{array}$ & $\begin{array}{c}11.403 * * * \\
(3.885) \\
\end{array}$ \\
\hline Observations & 3,657 & 3,657 & 3,657 & 3,320 & 3,320 & 3,320 \\
\hline R-squared & 0.166 & 0.129 & 0.274 & 0.112 & 0.095 & 0.160 \\
\hline Mean & 38.67 & 24.68 & 12.11 & 14.18 & 7.410 & 5.325 \\
\hline
\end{tabular}


Table 7: Effect of Source Country Characteristics for Second-Generation Immigrants

\begin{tabular}{|c|c|c|c|c|c|c|}
\hline & $\begin{array}{l}\text { (1) } \\
\text { Total Non-Market } \\
\text { Work }\end{array}$ & $\begin{array}{c}\text { (2) } \\
\text { Housework }\end{array}$ & $\begin{array}{c}\text { (3) } \\
\text { Childcare }\end{array}$ & $\begin{array}{l}\text { (4) } \\
\text { Total Non-Market } \\
\text { Work }\end{array}$ & $\begin{array}{c}\text { (5) } \\
\text { Housework }\end{array}$ & $\begin{array}{c}\text { (6) } \\
\text { Childcare }\end{array}$ \\
\hline & \multicolumn{3}{|c|}{ Panel A. All Women } & \multicolumn{3}{|c|}{ Panel B. All Men } \\
\hline Parent Gender Gap Index (GGI) & $\begin{array}{l}-14.38 \\
(13.60)\end{array}$ & $\begin{array}{l}-10.07 \\
(7.615)\end{array}$ & $\begin{array}{l}-3.325 \\
(6.378)\end{array}$ & $\begin{array}{l}-1.274 \\
(9.402)\end{array}$ & $\begin{array}{l}-7.371 \\
(8.760)\end{array}$ & $\begin{array}{l}9.711^{*} \\
(5.157)\end{array}$ \\
\hline Parent GDP per Capita $(\$ 1,000 \mathrm{~s})$ & $\begin{array}{c}0.0402 \\
(0.0580)\end{array}$ & $\begin{array}{c}0.0400 \\
(0.0488)\end{array}$ & $\begin{array}{l}-0.0296 \\
(0.0238)\end{array}$ & $\begin{array}{c}0.139 * * * \\
(0.0453)\end{array}$ & $\begin{array}{c}0.117 * * * \\
(0.0361)\end{array}$ & $\begin{array}{c}-0.00966 \\
(0.0210)\end{array}$ \\
\hline Parent Source Country Fertility & $\begin{array}{l}-1.136 \\
(1.181)\end{array}$ & $\begin{array}{l}-0.922 \\
(0.905)\end{array}$ & $\begin{array}{l}-0.613 \\
(0.489)\end{array}$ & $\begin{array}{c}0.899 \\
(0.728)\end{array}$ & $\begin{array}{c}0.543 \\
(0.597)\end{array}$ & $\begin{array}{c}0.375 \\
(0.417)\end{array}$ \\
\hline Observations & 1,985 & 1,985 & 1,985 & 1,706 & 1,706 & 1,706 \\
\hline R-squared & 0.215 & 0.145 & 0.417 & 0.173 & 0.145 & 0.324 \\
\hline \multirow[t]{2}{*}{ Mean } & 28.59 & 17.66 & 8.628 & 15.86 & 10.34 & 4.021 \\
\hline & \multicolumn{3}{|c|}{ Panel C: Women With at Least One Child Under 18} & \multicolumn{3}{|c|}{ Panel D: Men With at Least One Child Under 18} \\
\hline Parent Gender Gap Index (GGI) & $\begin{array}{l}-18.79 \\
(11.69)\end{array}$ & $\begin{array}{l}-7.059 \\
(6.219)\end{array}$ & $\begin{array}{l}-9.528 \\
(8.402)\end{array}$ & $\begin{array}{c}34.14 * * * \\
(11.16)\end{array}$ & $\begin{array}{c}12.39 \\
(9.225)\end{array}$ & $\begin{array}{l}19.28^{*} \\
(9.975)\end{array}$ \\
\hline Parent GDP per Capita $(\$ 1,000$ s $)$ & $\begin{array}{c}0.0313 \\
(0.0498)\end{array}$ & $\begin{array}{c}0.0393 \\
(0.0366)\end{array}$ & $\begin{array}{l}-0.0299 \\
(0.0363)\end{array}$ & $\begin{array}{c}0.0584 \\
(0.0516)\end{array}$ & $\begin{array}{c}0.0699 \\
(0.0432)\end{array}$ & $\begin{array}{l}-0.0118 \\
(0.0371)\end{array}$ \\
\hline Parent Source Country Fertility & $\begin{array}{l}-1.196 \\
(1.160) \\
\end{array}$ & $\begin{array}{l}-0.580 \\
(0.827) \\
\end{array}$ & $\begin{array}{l}-1.232^{*} \\
(0.664) \\
\end{array}$ & $\begin{array}{l}1.952 * * \\
(0.797) \\
\end{array}$ & $\begin{array}{l}1.596^{* *} \\
(0.707) \\
\end{array}$ & $\begin{array}{c}0.810 \\
(0.759) \\
\end{array}$ \\
\hline Observations & 1,462 & 1,462 & 1,462 & 1,175 & 1,175 & 1,175 \\
\hline R-squared & 0.193 & 0.158 & 0.300 & 0.226 & 0.197 & 0.258 \\
\hline Mean & 33.31 & 17.91 & 13.62 & 17.39 & 9.469 & 6.825 \\
\hline $\begin{array}{l}\text { Notes: Data are from waves } 2003-2017 \text { o } \\
\text { immigrant respondents aged } 18-64 \text { who } \\
\text { include individuals who work zero hours } \\
\text { regressions include controls for the respo } \\
\text { children controls, which are continuous } \\
\text { respondent in addition to indicators for } \\
\text { weighted using ATUS sampling weights } \\
\text { p }<0.1) \text {. }\end{array}$ & $\begin{array}{l}\text { TUS. The unit of obser } \\
\text { ried with a spouse aged } \\
\text { t source country charact } \\
\text { age, age squared, educ } \\
\text { es for the number of chil } \\
\text { the spouse is a first- or } \\
\text { ed so that each year rece }\end{array}$ & $\begin{array}{l}\text { and race/ethnici } \\
\text { the age ranges } \\
\text { d-generation im } \\
\text { e same weight. }\end{array}$ & $\begin{array}{l}\text { s fixed effects } \\
\text { ind 13-17, as } \\
\text { years since n } \\
\text { idard errors cl }\end{array}$ & $\begin{array}{l}\text { dif she is an immigran } \\
\text { surve demographic con } \\
\text { aears since migration } \\
\text { at the parent's birthplace }\end{array}$ & $\begin{array}{l}\text { The sample in } \\
\text { ex couples are ex } \\
\text { otherwise corres } \\
\text { and survey year. } \\
\text { which correspon } \\
\text { d, and immigrat } \\
\text { are in parenthes }\end{array}$ & $\begin{array}{l}\text { d-generation } \\
\text { sample does } \\
\text { se of the father. A } \\
\text { ons also include } \\
\text { sed for the } \\
\text { Regressions are } \\
01,{ }^{* *} \text { p }<0.05, *\end{array}$ \\
\hline
\end{tabular}


Table 8: Effect of Wife Earning More Than Husband on Total Non-Market Work for Women

\begin{tabular}{|c|c|c|c|}
\hline Panel A: All Women & $(1)$ & $(2)$ & (3) \\
\hline Wife Earns More & $\begin{array}{c}1.939 * * * \\
(0.546)\end{array}$ & & \\
\hline Observations & 27,069 & & \\
\hline R-squared & 0.279 & & \\
\hline Mean & 29.60 & & \\
\hline \multicolumn{4}{|l|}{ Panel B: Native Women } \\
\hline Wife Earns More & $\begin{array}{c}1.528 * * \\
(0.606)\end{array}$ & & \\
\hline Observations & 20,665 & & \\
\hline R-squared & 0.261 & & \\
\hline Mean & 28.66 & & \\
\hline \multicolumn{4}{|l|}{ Panel C: Immigrant Women } \\
\hline Wife Earns More & $\begin{array}{c}4.533 * * * \\
(1.367)\end{array}$ & $\begin{array}{c}4.492 * * * \\
(1.469)\end{array}$ & $\begin{array}{l}-3.137 \\
(10.39)\end{array}$ \\
\hline GGI & & $\begin{array}{l}-12.42 \\
(9.925)\end{array}$ & $\begin{array}{l}-15.52 \\
(11.56)\end{array}$ \\
\hline Wife Earns More x GGI & & & $\begin{array}{c}11.48 \\
(15.66) \\
\end{array}$ \\
\hline Observations & 4,739 & 4,438 & 4,438 \\
\hline R-squared & 0.324 & 0.326 & 0.326 \\
\hline Mean & 33.56 & 34.00 & 34.00 \\
\hline \multicolumn{4}{|c|}{ Panel D: Second-Generation Women } \\
\hline Wife Earns More & $\begin{array}{c}0.947 \\
(2.345)\end{array}$ & $\begin{array}{c}1.709 \\
(3.220)\end{array}$ & $\begin{array}{l}-21.75 \\
(15.18)\end{array}$ \\
\hline Parent Source Country GGI & & $\begin{array}{l}-1.612 \\
(10.22)\end{array}$ & $\begin{array}{l}-12.61 \\
(13.55)\end{array}$ \\
\hline Wife Earns More x Parent GGI & & & $\begin{array}{c}34.54 \\
(23.67) \\
\end{array}$ \\
\hline Observations & 1,665 & 1,420 & 1,420 \\
\hline R-squared & 0.368 & 0.381 & 0.382 \\
\hline Mean & 30.02 & 30.19 & 30.19 \\
\hline
\end{tabular}

Notes: Data are from waves 2003-2017 of the ATUS. The unit of observation is an ATUS respondent. The dependent variable is measured in hours per week. The sample includes female respondents aged 18-64 who are married with a spouse aged 18-64 present in the household. Observations that fall on public holidays and same sex couples are excluded. The sample does include individuals who work zero hours. All regressions include controls for the wife's relative income, a cubic in the respondent's log earnings, a cubic in the spouse's log earnings, the log of total family earnings, the respondents' age, age squared, education, and race/ethnicity, and fixed effects for state, survey day, survey month, and survey year. Regressions also control for the number of children in the age ranges 0-5, 6-12, and 13-17, as well as for spouse demographic controls corresponding to those used for the respondent. In Panel C, regressions control for immigration-relevant controls for both the respondent and the spouse: years since migration, years since migration squared, and immigration cohort. Regressions in Panel $\mathrm{C}$ also include indicators for whether the spouse is a first- or second-generation immigrant. In Panel D, regressions include the immigrant-relevant controls for the spouse, as well as parent source country GDP per capita and fertility. Parent source country characteristics used in Panel D correspond to those of the mother if available and if she is an immigrant, and otherwise correspond to those of the father. Robust standard errors are in parentheses $(* * *$ $\left.\mathrm{p}<0.01,{ }^{* *} \mathrm{p}<0.05, * \mathrm{p}<0.1\right)$. Standard errors are clustered at the birthplace level in Panel C and are clustered at the parent's birthplace level in Panel D. 
Table 9: Effect of Wife Earning More Than Husband on Total Non-Market Work for Men

\begin{tabular}{|c|c|c|c|}
\hline Panel A: All Men & $(1)$ & (2) & (3) \\
\hline Wife Earns More & $\begin{array}{c}0.103 \\
(0.524) \\
\end{array}$ & & \\
\hline Observations & 25,043 & & \\
\hline R-squared & 0.134 & & \\
\hline Mean & 18.19 & & \\
\hline \multicolumn{4}{|l|}{ Panel B: Native Men } \\
\hline Wife Earns More & $\begin{array}{r}0.225 \\
(0.593) \\
\end{array}$ & & \\
\hline Observations & 19,350 & & \\
\hline R-squared & 0.134 & & \\
\hline Mean & 18.72 & & \\
\hline \multicolumn{4}{|l|}{ Panel C: Immigrant Men } \\
\hline Wife Earns More & $\begin{array}{c}0.654 \\
(1.695)\end{array}$ & $\begin{array}{l}-0.0739 \\
(1.493)\end{array}$ & $\begin{array}{c}-30.67 * * * \\
(11.40)\end{array}$ \\
\hline GGI & & $\begin{array}{c}17.97 * * \\
(8.260)\end{array}$ & $\begin{array}{c}6.489 \\
(8.741)\end{array}$ \\
\hline Wife Earns More x GGI & & & $\begin{array}{c}45.74 * * * \\
(16.88)\end{array}$ \\
\hline Observations & 4,278 & 3,995 & 3,995 \\
\hline R-squared & 0.171 & 0.180 & 0.181 \\
\hline Mean & 15.41 & 15.43 & 15.43 \\
\hline \multicolumn{4}{|l|}{ Panel D: Second-Generation Men } \\
\hline Wife Earns More & $\begin{array}{l}-2.485 \\
(2.279)\end{array}$ & $\begin{array}{c}-4.699 * * \\
(1.911)\end{array}$ & $\begin{array}{c}10.14 \\
(14.57)\end{array}$ \\
\hline Parent Source Country GGI & & $\begin{array}{l}-15.97 \\
(9.877)\end{array}$ & $\begin{array}{l}-10.19 \\
(11.92)\end{array}$ \\
\hline Wife Earns More x Parent GGI & & & $\begin{array}{l}-21.77 \\
(23.33) \\
\end{array}$ \\
\hline Observations & 1,415 & 1,199 & 1,199 \\
\hline R-squared & 0.192 & 0.233 & 0.233 \\
\hline Mean & 19.27 & 19.18 & 19.18 \\
\hline
\end{tabular}

Notes: Data are from waves 2003-2017 of the ATUS. The unit of observation is an ATUS respondent. The dependent variable is measured in hours per week. The sample includes male respondents aged 18-64 who are married with a spouse aged 18-64 present in the household. Observations that fall on public holidays and same sex couples are excluded. The sample does include individuals who work zero hours. All regressions include controls for the wife's relative income, a cubic in the respondent's log earnings, a cubic in the spouse's log earnings, the log of total family earnings, the respondents' age, age squared, education, and race/ethnicity, and fixed effects for state, survey day, survey month, and survey year. Regressions also control for the number of children in the age ranges 0-5, 6-12, and 13-17, as well as for spouse demographic controls corresponding to those used for the respondent. In Panel C, regressions control for immigration-relevant controls for both the respondent and the spouse: years since migration, years since migration squared, and immigration cohort. Regressions in Panel $\mathrm{C}$ also include indicators for whether the spouse is a first- or second-generation immigrant. In Panel D, regressions include the immigrant-relevant controls for the spouse, as well as parent source country GDP per capita and fertility. Parent source country characteristics used in Panel D correspond to those of the mother if available and if she is an immigrant, and otherwise correspond to those of the father. Robust standard errors are in parentheses $(* * *$ $\left.\mathrm{p}<0.01,{ }^{* *} \mathrm{p}<0.05, * \mathrm{p}<0.1\right)$. Standard errors are clustered at the birthplace level in Panel C and are clustered at the parent's birthplace level in Panel D. 
Table A1: Effect of Years Since Migration (YSM) on Non-Market Work for Immigrant Couples Migrating Together

\begin{tabular}{|c|c|c|c|c|c|c|c|}
\hline \multicolumn{4}{|c|}{ Panel A. All Women } & \multicolumn{4}{|c|}{ Panel B. All Men } \\
\hline & al Non-Mar & & & \multicolumn{3}{|c|}{ Total Non-Market } & \multirow[b]{2}{*}{ Childcare } \\
\hline YSM & Work & Housework & Childcare & YSM & Work & Housework & \\
\hline \multirow[t]{2}{*}{10} & -2.704 & -2.045 & -0.476 & 10 & -0.357 & -0.451 & 0.553 \\
\hline & $(1.860)$ & $(1.376)$ & $(0.717)$ & & $(0.925)$ & $(0.737)$ & $(0.663)$ \\
\hline \multirow[t]{2}{*}{20} & -4.421 & -3.602 & -0.848 & 20 & -1.158 & -1.273 & 0.936 \\
\hline & (3.133) & $(2.280)$ & $(1.246)$ & & $(1.486)$ & $(1.175)$ & $(1.247)$ \\
\hline \multirow[t]{2}{*}{30} & -5.150 & -4.671 & -1.114 & 30 & -2.404 & -2.465 & 1.149 \\
\hline & $(3.993)$ & $(2.882)$ & $(1.652)$ & & $(2.064)$ & $(1.501)$ & $(1.812)$ \\
\hline \multicolumn{4}{|c|}{ Panel C. Women With at Least One Child Under 18} & \multicolumn{4}{|c|}{ Panel D. Men With at Least One Child Under 18} \\
\hline \multicolumn{3}{|c|}{ Total Non-Market } & & \multicolumn{3}{|c|}{ Total Non-Market } & \\
\hline YSM & Work & Housework & Childcare & YSM & Work & Housework & Childcare \\
\hline \multirow[t]{2}{*}{10} & -2.866 & $-2.367 *$ & -0.584 & 10 & -0.886 & -0.118 & 0.052 \\
\hline & $(1.949)$ & $(1.202)$ & $(0.986)$ & & $(1.215)$ & $(1.013)$ & $(0.981)$ \\
\hline \multirow[t]{2}{*}{20} & $-6.536^{*}$ & $-5.243 * *$ & -1.412 & 20 & -2.231 & -0.919 & 0.243 \\
\hline & $(3.331)$ & $(2.115)$ & $(1.642)$ & & $(2.031)$ & (1.566) & (1.876) \\
\hline \multirow[t]{2}{*}{30} & $-11.010 * *$ & $-8.630 * * *$ & -2.484 & 30 & -4.034 & -2.404 & 0.574 \\
\hline & $(4.420)$ & $(2.989)$ & $(2.126)$ & & (2.963) & (1.840) & (2.837) \\
\hline
\end{tabular}

Notes: Effects are based on the models in Tables 3 and 4 corresponding to Columns 2, 5, and 8 for total non-market work, housework, and child care, respectively.

Coefficients are linear combinations of the relevant respondent and spouse years since migration and years since migration squared coefficients. Appropriately computed standard errors are in parentheses $(* * * \mathrm{p}<0.01, * * \mathrm{p}<0.05, * \mathrm{p}<0.1)$ 
Table A2: Effect of Source Country Characteristics on Non-Market Work for Immigrants, GGI Subindexes

\begin{tabular}{|c|c|c|c|c|c|c|}
\hline & $\begin{array}{c}\text { (1) } \\
\text { Total Non-Market } \\
\text { Work }\end{array}$ & $\begin{array}{c}\text { (2) } \\
\text { Housework }\end{array}$ & $\begin{array}{c}\text { (3) } \\
\text { Childcare }\end{array}$ & $\begin{array}{c}(4) \\
\text { Total Non-Market } \\
\text { Work }\end{array}$ & $\begin{array}{c}\text { (5) } \\
\text { Housework }\end{array}$ & $\begin{array}{c}\text { (6) } \\
\text { Childcare }\end{array}$ \\
\hline & \multicolumn{3}{|c|}{ Panel A: All Women } & \multicolumn{3}{|c|}{ Panel B: All Men } \\
\hline Index of Political Equality & $\begin{array}{c}5.882 \\
(4.754)\end{array}$ & $\begin{array}{c}5.045 \\
(3.734)\end{array}$ & $\begin{array}{c}1.067 \\
(2.404)\end{array}$ & $\begin{array}{c}0.405 \\
(4.226)\end{array}$ & $\begin{array}{c}1.434 \\
(3.514)\end{array}$ & $\begin{array}{l}-1.340 \\
(1.684)\end{array}$ \\
\hline Index of Health Equality & $\begin{array}{c}44.18 \\
(30.50)\end{array}$ & $\begin{array}{c}62.72 * * * \\
(21.38)\end{array}$ & $\begin{array}{l}-19.24 \\
(18.32)\end{array}$ & $\begin{array}{c}48.22 \\
(29.45)\end{array}$ & $\begin{array}{c}61.72 * * * \\
(23.14)\end{array}$ & $\begin{array}{l}-19.16 \\
(12.06)\end{array}$ \\
\hline Index of Economic Participation Equality & $\begin{array}{l}-8.173 \\
(4.928)\end{array}$ & $\begin{array}{c}-8.856^{* *} \\
(3.903)\end{array}$ & $\begin{array}{c}1.194 \\
(2.000)\end{array}$ & $\begin{array}{l}8.294 * * \\
(3.447)\end{array}$ & $\begin{array}{c}3.454 \\
(2.670)\end{array}$ & $\begin{array}{c}5.507 * * * \\
(1.811)\end{array}$ \\
\hline Index of Education Equality & $\begin{array}{c}-35.96^{* * *} \\
(7.396)\end{array}$ & $\begin{array}{c}-20.80^{* * *} \\
(5.975)\end{array}$ & $\begin{array}{c}-14.37 * * * \\
(4.514)\end{array}$ & $\begin{array}{c}7.962 \\
(7.673)\end{array}$ & $\begin{array}{c}9.428 \\
(5.778)\end{array}$ & $\begin{array}{l}-5.097 \\
(3.607)\end{array}$ \\
\hline GDP per Capita $(\$ 1,000 \mathrm{~s})$ & $\begin{array}{l}0.149 * * \\
(0.0573)\end{array}$ & $\begin{array}{c}0.117 * * * \\
(0.0416)\end{array}$ & $\begin{array}{c}0.0223 \\
(0.0249)\end{array}$ & $\begin{array}{l}-0.0225 \\
(0.0510)\end{array}$ & $\begin{array}{l}-0.0544 \\
(0.0404)\end{array}$ & $\begin{array}{l}0.0435^{*} \\
(0.0260)\end{array}$ \\
\hline Fertility & $\begin{array}{l}0.0615 \\
(0.621) \\
\end{array}$ & $\begin{array}{c}0.651 \\
(0.533) \\
\end{array}$ & $\begin{array}{c}-0.589 * * \\
(0.276) \\
\end{array}$ & $\begin{array}{r}0.363 \\
(0.495) \\
\end{array}$ & $\begin{array}{c}0.169 \\
(0.428) \\
\end{array}$ & $\begin{array}{c}0.121 \\
(0.184) \\
\end{array}$ \\
\hline Observations & 6,192 & 6,192 & 6,192 & 5,458 & 5,458 & 5,458 \\
\hline R-squared & 0.201 & 0.128 & 0.355 & 0.095 & 0.083 & 0.159 \\
\hline \multirow[t]{2}{*}{ Mean } & 33.56 & 22.77 & 8.719 & 13.30 & 7.847 & 3.945 \\
\hline & \multicolumn{3}{|c|}{ Panel C: Women With at Least One Child Under 18} & \multicolumn{3}{|c|}{ Panel D: Men With at Least One Child Under 18} \\
\hline Index of Political Equality & $\begin{array}{c}3.527 \\
(6.658)\end{array}$ & $\begin{array}{c}1.792 \\
(4.896)\end{array}$ & $\begin{array}{c}1.579 \\
(3.796)\end{array}$ & $\begin{array}{l}-0.982 \\
(4.943)\end{array}$ & $\begin{array}{c}0.263 \\
(3.654)\end{array}$ & $\begin{array}{l}-0.0750 \\
(2.489)\end{array}$ \\
\hline Index of Health Equality & $\begin{array}{c}29.91 \\
(48.92)\end{array}$ & $\begin{array}{l}74.51 * * \\
(28.76)\end{array}$ & $\begin{array}{l}-29.75 \\
(33.51)\end{array}$ & $\begin{array}{c}17.33 \\
(34.29)\end{array}$ & $\begin{array}{l}45.04 * \\
(26.06)\end{array}$ & $\begin{array}{l}-30.50^{*} \\
(17.12)\end{array}$ \\
\hline Index of Economic Participation Equality & $\begin{array}{l}-9.408 \\
(6.176)\end{array}$ & $\begin{array}{c}-11.22 * * \\
(4.878)\end{array}$ & $\begin{array}{c}3.096 \\
(2.965)\end{array}$ & $\begin{array}{c}13.34 * * * \\
(3.891)\end{array}$ & $\begin{array}{l}5.542^{*} \\
(2.812)\end{array}$ & $\begin{array}{c}7.740 * * * \\
(2.419)\end{array}$ \\
\hline Index of Education Equality & $\begin{array}{c}-36.41 * * * \\
(11.73)\end{array}$ & $\begin{array}{c}-18.50 * * \\
(8.749)\end{array}$ & $\begin{array}{c}-21.28^{* * *} \\
(7.249)\end{array}$ & $\begin{array}{c}2.691 \\
(8.245)\end{array}$ & $\begin{array}{c}6.830 \\
(5.897)\end{array}$ & $\begin{array}{l}-5.535 \\
(5.422)\end{array}$ \\
\hline GDP per Capita $(\$ 1,000 \mathrm{~s})$ & $\begin{array}{c}0.213 * * * \\
(0.0722)\end{array}$ & $\begin{array}{l}0.129 * * \\
(0.0489)\end{array}$ & $\begin{array}{c}0.0542 \\
(0.0372)\end{array}$ & $\begin{array}{c}0.0130 \\
(0.0636)\end{array}$ & $\begin{array}{l}-0.0367 \\
(0.0411)\end{array}$ & $\begin{array}{l}0.0669^{*} \\
(0.0351)\end{array}$ \\
\hline Fertility & $\begin{array}{l}-0.0920 \\
(1.013) \\
\end{array}$ & $\begin{array}{c}0.487 \\
(0.806) \\
\end{array}$ & $\begin{array}{c}-0.884 * * \\
(0.431)\end{array}$ & $\begin{array}{l}-0.0890 \\
(0.537) \\
\end{array}$ & $\begin{array}{l}-0.227 \\
(0.466) \\
\end{array}$ & $\begin{array}{c}0.242 \\
(0.254) \\
\end{array}$ \\
\hline $\begin{array}{l}\text { Observations } \\
\text { R-squared }\end{array}$ & $\begin{array}{l}4,704 \\
0.152\end{array}$ & $\begin{array}{l}4,704 \\
0.128\end{array}$ & $\begin{array}{l}4,704 \\
0.266\end{array}$ & $\begin{array}{l}4,125 \\
0.099\end{array}$ & $\begin{array}{l}4,125 \\
0.090\end{array}$ & $\begin{array}{l}4,125 \\
0.128\end{array}$ \\
\hline Mean & 38.36 & 23.97 & 12.51 & 14.50 & 7.509 & 5.634 \\
\hline
\end{tabular}


Table A3: Effect of Wife Earning More Than Husband on Total Non-Market Work for Women, Dropping Relative Earnings from 0.489 to 0.50

\begin{tabular}{|c|c|c|c|}
\hline Panel A: All Women & $(1)$ & $(2)$ & (3) \\
\hline Wife Earns More & $\begin{array}{c}1.884 * * * \\
(0.585)\end{array}$ & & \\
\hline Observations & 26,314 & & \\
\hline R-squared & 0.278 & & \\
\hline Mean & 29.78 & & \\
\hline \multicolumn{4}{|l|}{ Panel B: Native Women } \\
\hline Wife Earns More & $\begin{array}{c}1.541 * * \\
(0.647)\end{array}$ & & \\
\hline Observations & 20,103 & & \\
\hline R-squared & 0.261 & & \\
\hline Mean & 28.81 & & \\
\hline \multicolumn{4}{|l|}{ Panel C: Immigrant Women } \\
\hline Wife Earns More & $\begin{array}{c}4.617 * * * \\
(1.650)\end{array}$ & $\begin{array}{c}4.512 * * \\
(1.780)\end{array}$ & $\begin{array}{c}-2.483 \\
(10.90)\end{array}$ \\
\hline GGI & & $\begin{array}{l}-11.48 \\
(10.32)\end{array}$ & $\begin{array}{c}-14.43 \\
(12.17)\end{array}$ \\
\hline Wife Earns More x GGI & & & $\begin{array}{c}10.54 \\
(16.31) \\
\end{array}$ \\
\hline Observations & 4,602 & 4,315 & 4,315 \\
\hline R-squared & 0.322 & 0.323 & 0.323 \\
\hline Mean & 33.82 & 34.28 & 34.28 \\
\hline \multicolumn{4}{|c|}{ Panel D: Second-Generation Women } \\
\hline Wife Earns More & $\begin{array}{l}-0.436 \\
(2.768)\end{array}$ & $\begin{array}{c}0.321 \\
(3.749)\end{array}$ & $\begin{array}{c}-23.44 \\
(15.72)\end{array}$ \\
\hline Parent Source Country GGI & & $\begin{array}{l}-1.310 \\
(10.65)\end{array}$ & $\begin{array}{l}-12.85 \\
(14.02)\end{array}$ \\
\hline Wife Earns More x Parent GGI & & & $\begin{array}{c}34.95 \\
(24.79) \\
\end{array}$ \\
\hline Observations & 1,609 & 1,372 & 1,372 \\
\hline R-squared & 0.370 & 0.382 & 0.383 \\
\hline Mean & 30.33 & 30.47 & 30.47 \\
\hline
\end{tabular}

Notes: Data are from waves 2003-2017 of the ATUS. The unit of observation is an ATUS respondent. The dependent variable is measured in hours per week. The sample includes female respondents aged 18-64 who are married with a spouse aged 18-64 present in the household. Observations that fall on public holidays and same sex couples are excluded. The sample does include individuals who work zero hours. All regressions include controls for the wife's relative income, a cubic in the respondent's log earnings, a cubic in the spouse's log earnings, the log of total family earnings, the respondents' age, age squared, education, and race/ethnicity, and fixed effects for state, survey day, survey month, and survey year. Regressions also control for the number of children in the age ranges 0-5, 6-12, and 13-17, as well as for spouse demographic controls corresponding to those used for the respondent. In Panel C, regressions control for immigration-relevant controls for both the respondent and the spouse: years since migration, years since migration squared, and immigration cohort. Regressions in Panel $\mathrm{C}$ also include indicators for whether the spouse is a first- or second-generation immigrant. In Panel D, regressions include the immigrant-relevant controls for the spouse, as well as parent source country GDP per capita and fertility. Parent source country characteristics used in Panel D correspond to those of the mother if available and if she is an immigrant, and otherwise correspond to those of the father. Robust standard errors are in parentheses (*** $\left.\mathrm{p}<0.01,{ }^{*} \mathrm{p}<0.05, * \mathrm{p}<0.1\right)$. Standard errors are clustered at the birthplace level in Panel $\mathrm{C}$ and are clustered at the parent's birthplace level in Panel D. 
Table A4: Effect of Wife Earning More Than Husband on Total Non-Market Work for Men, Dropping Relative Earnings from 0.489 to 0.50

\begin{tabular}{|c|c|c|c|}
\hline Panel A: All Men & (1) & (2) & (3) \\
\hline Wife Earns More & $\begin{array}{c}0.149 \\
(0.546)\end{array}$ & & \\
\hline Observations & 24,346 & & \\
\hline R-squared & 0.135 & & \\
\hline Mean & 18.20 & & \\
\hline \multicolumn{4}{|l|}{ Panel B: Native Men } \\
\hline Wife Earns More & $\begin{array}{c}0.383 \\
(0.614) \\
\end{array}$ & & \\
\hline Observations & 18,817 & & \\
\hline R-squared & 0.135 & & \\
\hline Mean & 18.72 & & \\
\hline \multicolumn{4}{|l|}{ Panel C: Immigrant Men } \\
\hline Wife Earns More & $\begin{array}{c}0.608 \\
(1.939)\end{array}$ & $\begin{array}{l}-0.104 \\
(1.790)\end{array}$ & $\begin{array}{c}-30.70 * * * \\
(11.60)\end{array}$ \\
\hline GGI & & $\begin{array}{l}18.28 * * \\
(8.331)\end{array}$ & $\begin{array}{c}6.438 \\
(8.958)\end{array}$ \\
\hline Wife Earns More x GGI & & & $\begin{array}{c}45.73 * * * \\
(17.10)\end{array}$ \\
\hline Observations & 4,161 & 3,888 & 3,888 \\
\hline R-squared & 0.174 & 0.184 & 0.185 \\
\hline Mean & 15.43 & 15.44 & 15.44 \\
\hline \multicolumn{4}{|l|}{ Panel D: Second-Generation Men } \\
\hline Wife Earns More & $\begin{array}{l}-3.848 \\
(2.675)\end{array}$ & $\begin{array}{c}-6.324 * * * \\
(2.360)\end{array}$ & $\begin{array}{c}8.092 \\
(14.62)\end{array}$ \\
\hline Parent Source Country GGI & & $\begin{array}{l}-16.11 \\
(10.18)\end{array}$ & $\begin{array}{l}-10.21 \\
(12.56)\end{array}$ \\
\hline Wife Earns More x Parent GGI & & & $\begin{array}{l}-21.16 \\
(23.93)\end{array}$ \\
\hline Observations & 1,368 & 1,157 & 1,157 \\
\hline R-squared & 0.194 & 0.240 & 0.240 \\
\hline Mean & 19.45 & 19.38 & 19.38 \\
\hline
\end{tabular}

Notes: Data are from waves 2003-2017 of the ATUS. The unit of observation is an ATUS respondent. The dependent variable is measured in hours per week. The sample includes male respondents aged 18-64 who are married with a spouse aged 18-64 present in the household. Observations that fall on public holidays and same sex couples are excluded. The sample does include individuals who work zero hours. All regressions include controls for the wife's relative income, a cubic in the respondent's log earnings, a cubic in the spouse's log earnings, the log of total family earnings, the respondents' age, age squared, education, and race/ethnicity, and fixed effects for state, survey day, survey month, and survey year. Regressions also control for the number of children in the age ranges 0-5, 6-12, and 13-17, as well as for spouse demographic controls corresponding to those used for the respondent. In Panel C, regressions control for immigration-relevant controls for both the respondent and the spouse: years since migration, years since migration squared, and immigration cohort. Regressions in Panel $\mathrm{C}$ also include indicators for whether the spouse is a first- or second-generation immigrant. In Panel D, regressions include the immigrant-relevant controls for the spouse, as well as parent source country GDP per capita and fertility. Parent source country characteristics used in Panel D correspond to those of the mother if available and if she is an immigrant, and otherwise correspond to those of the father. Robust standard errors are in parentheses (*** $\left.\mathrm{p}<0.01,{ }^{* *} \mathrm{p}<0.05, * \mathrm{p}<0.1\right)$. Standard errors are clustered at the birthplace level in Panel C and are clustered at the parent's birthplace level in Panel D. 